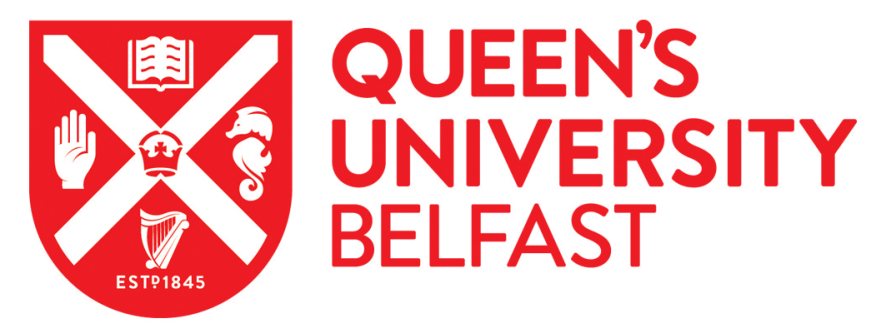

\title{
Dapivirine-releasing vaginal rings produced by plastic freeforming additive manufacturing
}

Welsh, N. R., Malcolm, R. K., Devlin, B., \& Boyd, P. (2019). Dapivirine-releasing vaginal rings produced by plastic freeforming additive manufacturing. International Journal of Pharmaceutics.

https://doi.org/10.1016/j.ijpharm.2019.118725

\section{Published in:}

International Journal of Pharmaceutics

\section{Document Version:}

Peer reviewed version

\section{Queen's University Belfast - Research Portal:}

Link to publication record in Queen's University Belfast Research Portal

\section{Publisher rights}

Copyright 2019 Elsevier B. V.

This manuscript is distributed under a Creative Commons Attribution-NonCommercial-NoDerivs License

(https://creativecommons.org/licenses/by-nc-nd/4.0/), which permits distribution and reproduction for non-commercial purposes, provided the author and source are cited.

\section{General rights}

Copyright for the publications made accessible via the Queen's University Belfast Research Portal is retained by the author(s) and / or other copyright owners and it is a condition of accessing these publications that users recognise and abide by the legal requirements associated with these rights.

Take down policy

The Research Portal is Queen's institutional repository that provides access to Queen's research output. Every effort has been made to ensure that content in the Research Portal does not infringe any person's rights, or applicable UK laws. If you discover content in the Research Portal that you believe breaches copyright or violates any law, please contact openaccess@qub.ac.uk. 
Elsevier Editorial System(tm) for

International Journal of Pharmaceutics or its open access mirror Manuscript Draft

Manuscript Number: IJP-D-19-01649R1

Title: Dapivirine-releasing vaginal rings produced by plastic freeforming additive manufacturing

Article Type: Research Paper

Section/Category:

Keywords: HIV microbicide; thermoplastic polyurethane vaginal ring; dapivirine; injection molding; additive manufacturing

Corresponding Author: Dr. Peter Boyd, PhD

Corresponding Author's Institution: Queen's University of Belfast

First Author: Nicole R Welsh, PhD

Order of Authors: Nicole R Welsh, PhD; Karl Malcolm, PhD; Brid Devlin, PhD; Peter Boyd, PhD

Abstract: Here we report the first use of an additive manufacturing (AM) technique based on high pressure material jetting of molten thermoplastic for the fabrication of dapivirine (DPV) loaded vaginal rings (VRS). The VRs are compared to those produced conventionally using injection molding (IM). VRs (outer diameter $54.0 \mathrm{~mm}$, cross-sectional diameter $4.0 \mathrm{~mm}$ ) were manufactured by either injection molding or Arburg Plastic Freeforming $(\mathrm{APF})$ - a proprietary droplet deposition modelling (DDM) process, using medical grade thermoplastic polyurethanes (TPUs) loaded with $10 \% \mathrm{w} / \mathrm{w}$ DPV . This unique DDM process was used to produce rings of 100,50 and $10 \%$ matrix infill density. DDM printed VRs with 10\% density (57-62 mg drug load) exhibited up to seven-fold increase in DPV release compared to injection molded rings containing 190-194 mg DPV. This work has shown that DDM using the APF technique can be used to manufacture drug delivery devices of varying geometries, densities and surface areas to give precise levels of control over the drug release kinetics. This work presents a new opportunity to increase the release of poorly watersoluble compounds or to achieve desired dosing levels using lower drug loadings than those required using conventional thermoplastic processing techniques.

Research Data Related to this Submission

There are no linked research data sets for this submission. The following reason is given:

Data will be made available on request 
3

4

5

6

7

8

9

10

\section{Dapivirine-releasing vaginal rings produced by plastic freeforming additive manufacturing}

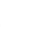

Nicole R. Welsh ${ }^{1}$, R. Karl Malcolm ${ }^{1}$, Brid Devlin $^{2}$, Peter Boyd $^{1}$ * 5 Short title: Additive manufacturing of dapivirine loaded vaginal rings

\author{
${ }^{1}$ School of Pharmacy, Queen's University Belfast, Belfast BT9 7BL, UK;
}

${ }^{2}$ International Partnership for Microbicides, Silver Spring, MD 20910, USA

*Corresponding author. Tel: +44 (0)28 9097 2623; E-mail: p.boyd@qub.ac.uk

Keywords: HIV microbicide; thermoplastic polyurethane vaginal ring; dapivirine; injection molding; additive manufacturing 


\section{Abstract}

16 Here we report the first use of an additive manufacturing (AM) technique based on high

17 pressure material jetting of molten thermoplastic for the fabrication of dapivirine (DPV)

18 loaded vaginal rings (VRs). The VRs are compared to those produced conventionally using

19 injection molding (IM). VRs (outer diameter $54.0 \mathrm{~mm}$, cross-sectional diameter $4.0 \mathrm{~mm}$ )

20 were manufactured by either injection molding or Arburg Plastic Freeforming (APF) - a

21 proprietary droplet deposition modelling (DDM) process, using medical grade thermoplastic

22 polyurethanes (TPUs) loaded with $10 \% \mathrm{w} / \mathrm{w}$ DPV. This unique DDM process was used to

23 produce rings of 100,50 and $10 \%$ matrix infill density. DDM printed VRs with $10 \%$ density

24 (57-62 mg drug load) exhibited up to seven-fold increase in DPV release compared to

25 injection molded rings containing 190-194 mg DPV. This work has shown that DDM using

26 the APF technique can be used to manufacture drug delivery devices of varying geometries,

27 densities and surface areas to give precise levels of control over the drug release kinetics.

28 This work presents a new opportunity to increase the release of poorly water-soluble

29 compounds or to achieve desired dosing levels using lower drug loadings than those required

30 using conventional thermoplastic processing techniques. 


\section{Introduction}

32 The concept of sustained, localised drug administration to the human vagina using a 33 polymeric ring was first published in 1970 (Duncan, 1970; Mishell and Lumkin, 1970). 34 Seven vaginal ring (VR) products have since been approved, each delivering one or two steroid molecules for applications in hormone replacement or contraception. Although VR design and manufacturing methods vary according to each product, they are broadly split into either matrix (monolith) or reservoir (core/sheath) types, manufactured using either injection molding, extrusion or combinations thereof (Malcolm et al., 2015). Estring ${ }^{\circledR}$, Femring ${ }^{\circledR}$, Progering ${ }^{\circledR}$, Fertiring ${ }^{\circledR}$ and Annovera ${ }^{\circledR}$ are silicone elastomer based VRs while Nuvaring® and Ornibel ${ }^{\circledR}$ make use of polyurethane and/or ethylene vinyl acetate thermoplastic polymers.

Additive manufacturing (AM) encompasses a wide range of processes and has been reviewed for its use in a number of pharmaceutical applications (Jonathan and Karim, 2016). Fused deposition modelling (FDM $\left.{ }^{\mathrm{TM}}\right)$ is the most common technique, involving the continuous extrusion of molten drug-loaded thermoplastic formulations through a digitally controlled nozzle to create three dimensional parts generated from digital data. FDM has been used to produce oral dosage forms (Goyanes et al., 2015, 2014; Maroni et al., 2017; Okwuosa et al., 2018), intrauterine systems (Genina et al., 2016), implants (Espalin et al., 2010), scaffolds (Rai et al., 2005) and vaginal rings (Fu et al., 2018; Welsh et al., 2018, 2016). Droplet deposition modelling (DDM) is a type of AM that produces discrete streams of material during deposition. Its main area of application has been in inkjet systems (Scoutaris et al., 2011). More viscous liquids, including thermosetting polymers such as silicones and resins,

54 have been processed by DDM using 3D plotting, operating at material pressures of 0.8 bar, nozzle diameters of $200 \mu \mathrm{m}$ and dispensing into a liquid medium (Landers and Mülhaupt, 
2000). The first use of a hot wax, inkjet printing process was recently reported to produce tuneable drug delivery devices (Kyobula et al., 2017), though this method does not appear to be suitable for highly viscous thermoplastic melts.

Arburg Plastic Freeforming (APF) (Kraibuhler et al., 2018; Kraibuhler and Duffner, 2018) refers to a thermoplastic droplet deposition modelling capable of operating at temperatures greater than $300^{\circ} \mathrm{C}$ and pressures in excess of 400 bar. The technique is capable of processing the majority of granulated polymer feedstocks commonly used in injection molding processes and without requiring solvents or specialist resins.

Acquired immune deficiency syndrome (AIDS) is an overarching group of potentially lifethreatening infections or illnesses which arise in the immune systems of people compromised by the human immunodeficiency virus (HIV). In 2016, there were 36.7 million people globally living with HIV, with 1 million deaths occurring as a result of AIDS-related illnesses (UNAIDS, 2017). In efforts to end the AIDS epidemic by the year 2030, researchers have been developing an array of preventative treatments (Abdool et al., 2010; Alexandre et al., 2016; Boyd et al., 2016; Malcolm et al., 2015; Van Damme et al., 2000). A matrix-type silicone elastomer VR offering 28-day release of dapivirine (DPV) - a nonnucleoside reverse transcriptase inhibitor - has been developed by the International Partnership of Microbicides (IPM). The results of two Phase III clinical trials (ASPIRE and the Ring Study) completed in 2016 showed that women across all ages using the DPV ring had a 37 and 31\% reduced risk of contracting HIV respectively, (Baeten et al., 2016; Nel et al., 2016), with approximately 4 $\mathrm{mg}(16 \%$ of the original $25 \mathrm{mg}$ loading) of DPV released during 28 day ring use (Nel et al., 2016). This relatively low percentage of dapivirine release is attributed to both its poor aqueous solubility $(<1 \mu \mathrm{g} / \mathrm{mL})$ and its relatively low permeation rate through the silicone 
81 elastomer matrix. Strategies to increase the rate of dapivirine release from a VR device would therefore be useful.

84 There is considerable interest in the use of biocompatible thermoplastics for development of 85 microbicide-releasing VRs, particularly given the generally enhanced solubility of drugs in 86 thermoplastics compared to silicone elastomers (Clark et al., 2012; Gupta et al., 2008; 87 Johnson et al., 2010; Koutsamanis et al., 2019; van Laarhoven et al., 2002). For example, when encapsulated in a hydrophobic TPU up to a drug-loading of $20 \% \mathrm{w} / \mathrm{w}$, dapivirine exists in the more soluble amorphous form. By comparison, in silicone elastomers, DPV exists

90 primarily in the crystalline form (Faheem et al., 2009; Fetherston et al., 2013; Gupta et al., 91 2008; McCoy et al., 2017).

92

93 Thermoplastic, high pressure, droplet deposition modelling, as employed in this study using 94 the Freeformer printer (Fig. 1), utilises a piezo controlled shut-off nozzle to discreetly control 95 the exiting of material from the nozzle as a continuous strand of droplets to create individual 96 layers, giving precise levels of control over a device's design and morphology. Properties 97 including geometry, density and surface area can be manipulated in ways that would be impossible using conventional thermoplastic processing techniques. While this 3D printing technique is applicable as a platform technology, in this work, it was hypothesised that 100 increasing the exposed surface area of the ring by modulating the in-fill density via the DDM 101 process could be used to increase the amount of poorly water-soluble DPV released from 102 TPU based vaginal rings. 


\section{2. Materials and methods}

105

106

107

108

109

110

111

112

113

114

115

116

117

118

119

120

121

122

123

124

125

126

127

\subsection{Materials}

Thermoplastic polyurethanes PY-PT87AE (T87) and PY-PT60DE (T60) were supplied from Lubrizol (Ohio, USA). T87 had a Shore-A hardness of 87 whilst T60 had a Shore-D value of 60. Micronised dapivirine was supplied by IPM (Maryland, USA). HPLC grade isopropyl alcohol (IPA), acetonitrile (ACN), methanol and acetone were purchased from SigmaAldrich (Gillingham, UK). Potassium phosphate monobasic, dihydrogen sodium phosphate, tween 80 and $85 \%$ phosphoric acid were also purchased from Sigma-Aldrich (Gillingham, UK). HPLC grade water was obtained using a Millipore Direct-Q 3 UV Ultrapure Water System (Watford, UK).

\subsection{Thermal analysis}

Thermogravimetric analysis (TGA) of supplied raw materials T87, T60 and DPV was performed using a Q50 instrument (TA Instruments, UK). Samples ( $\mathrm{n}=3 ; 2-20 \mathrm{mg}$ ) were prepared in open aluminium pans and heated from 25 to $250^{\circ} \mathrm{C}$ at $20^{\circ} \mathrm{C} \min ^{-1}$. Differential scanning calorimetry (DSC; Q20 or Q100 instrument, TA Instruments, UK) analysis was carried out for raw materials and TPU/DPV polymeric blends under a nitrogen atmosphere. Samples $(\mathrm{n}=3 ; 2-10 \mathrm{mg})$ were weighed into aluminium pans and sealed. Samples were heated from either $-90^{\circ} \mathrm{C},-50^{\circ} \mathrm{C}$ or $25^{\circ} \mathrm{C}$ to $250^{\circ} \mathrm{C}$, at $20^{\circ} \mathrm{C} \mathrm{min}^{-1}$. In all instances, peak midpoint values were reported. Data was analysed and extrapolated using TA Universal Analysis software version 4.5A (TA Instruments, UK). 


\subsection{Hot Melt Extrusion}

129 Polymers were dried according to the supplier's recommendations; $4-6 \mathrm{~h}$ at $60^{\circ} \mathrm{C}$ in a fan circulation oven (LTE OP100, LTE-Scientific Ltd., UK) prior to extrusion. Drug-loaded filaments containing TPU with up to $10 \% \mathrm{w} / \mathrm{w}$ DPV were compounded using a Minilab II (Thermo-Haake, UK). T87/DPV and T60/DPV blends were extruded at $185^{\circ} \mathrm{C}$ and $195^{\circ} \mathrm{C}$ respectively, with a screw speed of $60 \mathrm{rpm}$. The extrudate was collected, pelletised (Thermo Scientific Varicut Pelletizer, Thermo Electron Corp., Germany) to produce pellets $\sim 2.0 \mathrm{~mm}$ and extruded a second time using the same conditions to ensure homogeneity of the drug. The outer diameter of the filament was controlled to $1.5 \mathrm{~mm} \pm 1.0 \mathrm{~mm}$ by adjusting the speed of the haul off mechanism. Drug-loaded filament was finally pelletised to produce pellets $\sim 2.0 \mathrm{~mm}$ in length suitable for use in the DDM or IM process.

\subsection{Computer Aided Design}

141 Computer aided design (CAD) software (Solid Edge ST7, Siemens, Germany) was used to design 3D models representing the geometry of the drug delivery devices. Models were exported in the stereolithography (.STL) file format for use in the proprietary slicing software

144 (Freeformer software V2.2, Arburg, Germany) for the DDM printer. Additionally, modelling of the DDM VRs mass and surface area at different densities was performed by recreating the AM, droplet-based structures using the CAD software and relative material properties of the 147 VRs.

\subsection{Additive Manufacturing}

150 Prior to printing devices, materials were qualified on the 3D printer, (Freeformer, Arburg, 151 Germany) by adjusting the processing conditions (temperature and discharge number 152 related to material deposition volume) until droplets of a suitable aspect ratio (width/height) 
were continuously deposited. A defined cubic geometry $(20 \times 20 \times 20 \mathrm{~mm})$ was printed using layer thicknesses defined by the measured droplet height and respective aspect ratio to confirm the settings were optimised. In some instances, a scaling profile was also required to account for shrinkage, however this was dependent on the behaviour of each individual material. For the manufacture of VRs, T87/DPV pellets were processed using the following temperature profile: discharge nozzle, $180^{\circ} \mathrm{C}$; barrel zone $2,160^{\circ} \mathrm{C}$; barrel zone $1,150^{\circ} \mathrm{C}$ with a discharge number of $45 \%, 0.20 \mathrm{~mm}$ layer height and an aspect ratio of 1.15 . T60/DPV pellets were processed at $165^{\circ} \mathrm{C}$ in all three heating zones, discharge number of $40 \%$, layer height of $0.22 \mathrm{~mm}$ and a droplet aspect ratio of 0.97 .

\subsection{Injection Molding}

Drug-free and drug-loaded pellets were dried prior to injection molding at $60^{\circ} \mathrm{C}$ for $4-6 \mathrm{hr}$. TPU pellets (T87 and T60) were used as supplied for the manufacture of drug-free VRs (cross-sectional diameter $4.00 \mathrm{~mm}$, outer diameter $54.00 \mathrm{~mm}$ ). Drug-loaded filament (outer diameter $1.50 \pm 0.1 \mathrm{~mm}$ ) was pelletised using a Thermo Scientific Varicut Pelletizer (Thermo Electron Corp., Germany) to produce pellets $\sim 2.0 \mathrm{~mm}$ in length. Matrix-type, VRs (crosssectional diameter $4.00 \mathrm{~mm}$, outer diameter $54.00 \mathrm{~mm}$ ) were manufactured using a Babyplast 6/10 P horizontal injection molding machine (Molteno LC, ITA). Drug-loaded T87 pellets were melted using the following temperature profile: plastification unit, $180^{\circ} \mathrm{C}$; injection chamber, $182^{\circ} \mathrm{C}$; nozzle, $185^{\circ} \mathrm{C}$ and injected at a pressure of $9000 \mathrm{kPa}$. Drug-loaded $\mathrm{T} 60$ pellets were melted at $195^{\circ} \mathrm{C}$ across all three eating zones and injected at a pressure of 9000 $\mathrm{kPa}$. Solidified VRs (cooling time: $15 \mathrm{sec}$ ) were demolded and stored at ambient temperature until future testing.

\subsection{Ring appearance and weight}


178 Ring weight was recorded using a 4-point balance. Ring outer diameter (OD) and cross179 sectional diameter (CSD) were measured using $150 \mathrm{~mm}$ digital callipers (RS Components, $180 \mathrm{UK})$.

\subsection{Mechanical testing}

183 TPU VRs (cross-sectional diameter $4.00 \mathrm{~mm}$, outer diameter $54.00 \mathrm{~mm}$ ) and commercial 184 VRs, Femring and Estring, underwent compression testing using a TA.XT plus Texture 185 Analyser (Stable Micro Systems, Surrey, UK). VRs were tested using the compression mode, with a target distance of $5.00 \mathrm{~mm}$ and a test speed of $2 \mathrm{~mm} / \mathrm{s}$. Six compression cycles were completed, with the maximum force value being recorded for the last five cycles and averaged.

\subsection{Imaging}

191 Digital images of devices were taken using either a VHX-700F digital microscope (Keyence, 192 $\sec )$.

\subsection{In vitro release testing}

196 For all formulations, $0.2 \%$ Tween 80 in water was used as the dissolution media. Samples $197(\mathrm{n}=6)$ were initially placed in glass bottles with an appropriate volume of dissolution media to 198 ensure sink conditions were maintained $(1000 \mathrm{~mL}$ of dissolution media for devices with $199100 \%$ infill density, and $500 \mathrm{~mL}$ for those with 50 and $10 \%$ infill density). Samples were stored in an orbital shaking incubator (Infors HT AGCH-4103) at $37^{\circ} \mathrm{C}, 60 \mathrm{rpm}$ and $25 \mathrm{~mm}$ orbital throw. Daily samples $(1 \mathrm{~mL})$ were taken followed by total volume replacement of the release media. From Day 1 until the end of the study, $500 \mathrm{~mL}$ was used for $100 \%$ infill 
density samples and $250 \mathrm{~mL}$ for 50 and $10 \%$ infill density samples, except on Fridays where $2041000 \mathrm{~mL}$ and $500 \mathrm{~mL}$, respectively, were used as daily sampling did not occur over weekends. Drug release was quantified using HPLC analysis.

206

207

\subsection{HPLC analysis}

208 DPV was quantified using HPLC (Alliance, Waters e2695 Separation Module, w2489 UV 209 detector) with UV detection at $210 \mathrm{~nm}$. Isocratic separation was achieved using a 210 Phenomenex C18 $(5 \mu \mathrm{m}$ pore size, $150 \times 4.60 \mathrm{~mm})$ analytical column with a fitted guard 211 cartridge. HPLC was performed using a mobile phase of $7.7 \mathrm{mM}$ potassium phosphate 212 monobasic, $\mathrm{pH}$ adjusted to 3.0 using phosphoric acid, and HPLC grade ACN (55:45) at a 213 flow rate of $1.0 \mathrm{~mL} / \mathrm{min}$ for $10 \mathrm{~min}$ with an injection volume of $25 \mu \mathrm{L}$. The column 214 temperature was set to $35 \pm 5^{\circ} \mathrm{C}$.

215

216

\subsection{Content Assay}

217 Pellets of the extrudate were assayed for drug content, while IM and DDM-printed VR samples were radially cut into segments $\sim 2 \mathrm{~mm}$ in length using a scalpel. Samples $(\mathrm{n}=4)$ were placed in $100 \mathrm{~mL}$ glass bottles with a suitable volume $(100 \mathrm{~mL})$ of extraction media (acetone) and stored in an orbital shaking incubator (Infors $\mathrm{HT}$ AGCH-4103) at $37^{\circ} \mathrm{C}, 60 \mathrm{rpm}$ and 25 $\mathrm{mm}$ orbital throw. After $24 \mathrm{~h}$, DPV solutions were sampled (1 mL) and diluted (1 in 100) in $50 \% \mathrm{ACN}$ in water. The solution was then sampled $(1 \mathrm{~mL})$ for subsequent HPLC analysis.

\subsection{Statistical Analysis}

225 Statistical analysis was carried out on in-vitro release data using one-way analysis of variance (ANOVA) (GraphPad Prism version 6 for Windows, GraphPad Software, San Diego, CA). 
227 Post-hoc comparisons were performed using Tukey's Multiple Comparisons test. A 228 significant level of $\mathrm{p}<0.05$ was accepted to denote significance in all cases. 


\section{Results and Discussion}

230

231

232

233

234

235

236

237

238

239

240

241

242

243

244

245

246

247

248

249

250

251

252

\subsection{Thermal analysis}

TPU grades $\mathrm{T} 87$ and $\mathrm{T} 60$ showed weight loss less than $0.70 \%$ at the maximum processing temperature of $195^{\circ} \mathrm{C}$, indicating thermal stability under IM and DDM processing conditions (Fig. 2). Weight loss (\%) up to $100^{\circ} \mathrm{C}$ was attributed to the loss of absorbed water. The DSC thermal trace for DPV shows two endotherms occurring at $104^{\circ} \mathrm{C}$ and $223^{\circ} \mathrm{C}$ (Fig. 3). The first endotherm represents a polymorphic transition from crystalline DPV form I to form II, whilst the second endotherm is the DPV melt endotherm (McCoy et al., 2017; Murphy et al., 2014). Thermal analysis of drug-loaded TPU formulations showed that the DPV melt endotherm was absent, indicating that DPV was either in the amorphous state or fully solubilised within the TPU at the experimental conditions (Fig. 3). This result was in agreement with previous studies demonstrating complete solubilisation of DPV in TPU matrices up to drug-loadings of 20\% w/w (Gupta et al., 2008).

\subsection{Manufacture}

Filament blends (TPU with 10\% w/w DPV) were successfully extruded with a diameter of $1.50 \pm 0.10 \mathrm{~mm}$. Pelletised material from T87/DPV extrudate exhibited greater tack adhesion to itself compared to the T60/DPV granulate, likely due to a decrease in the proportion of hard to soft segments between the 60D and T87 TPU grades, though no bridging issues were observed in the feed hoppers of the injection molder or Freeformer printer during ring manufacture (Sánchez-Adsuar, 2000). VRs were successfully fabricated from T87/DPV and T60/DPV granulates using both injection molding or APF DDM.

\subsection{Mechanical Testing}


253 Drug-free and 10\% DPV-loaded TPU based VRs (OD: $54.00 \mathrm{~mm}$, CSD: $4.00 \mathrm{~mm}$ ) were manufactured using a Babyplast 6/10 P horizontal injection molding machine (Chronoplast SL, ESP). The maximum force to compress drug-free T87 and T60 VRs $(n=10)$ by a target distance of $5.00 \mathrm{~mm}$ was 0.71 and $6.12 \mathrm{~N}$, respectively (Fig. 4), determined to be a statistically significant difference $(\mathrm{p}>0.05)$. Drug-loaded T87 and T60 VRs required a maximum force of 0.16 to $0.80 \mathrm{~N}$ and 0.73 to $5.85 \mathrm{~N}$ respectively to compress VRs by a target distance of $5.00 \mathrm{~mm}$ as the ring density was increased from 10 to $100 \%$ (Fig. 4).

260

261

The maximum compressive force required for $5.00 \mathrm{~mm}$ compression of $\mathrm{T} 87$ rings was similar to the commercial VR, Femring (maximum compression force of $0.78 \mathrm{~N}$ ) (Fig. 4). It was decided that T87 and T60 would be suitable for the development of drug-loaded VRs manufactured by DDM and IM as the maximum compression force required for a $5.00 \mathrm{~mm}$ compression did not exceed that of commercial VRs (Estring ${ }^{\circledR}$, Femring ${ }^{\circledR}$ and Nuvaring $\left.{ }^{\circledR}\right)$ which required up to $\sim 9.0 \mathrm{~N}$ to compress rings through a specified distance (Promadej-Lanier 267 et al., 2009).

268

269

\subsection{Ring appearance and weight}

270 T87/DPV and T60/DPV IM rings were yellow and translucent in appearance (Fig. 6).

271 T87/DPV and T60/DPV rings fabricated by APF DDM, were whiter, with a yellow tinge and 272 less translucent (Fig. 5). All TPU/DPV rings manufactured by IM and DDM were considered 273 to be dimensionally accurate as they were within the specified acceptance criteria (OD: 54.00 $274 \pm 2.70 \mathrm{~mm}, \mathrm{CSD}: 4.00 \pm 0.20 \mathrm{~mm}$ ) (Table 1). The uniform, porous structure created by APF

275 DDM at lower densities of printing was readily observable in the 10 and $50 \%$ dense VRs 276 (Fig. 5). There was significant visual contrast between all DDM VR outer surfaces and those 277 produced via IM (Fig. 6). 


\subsection{Microscopy}

280 Representative microscopy images showing differences in surface morphology as a function 281 of the corresponding infill density (\%) used to print the sample are presented in Fig. 5. VRs 282 manufactured by DDM had a rougher surface finish than IM VRs, with individual droplets clearly being discerned. IM VRs were manufactured by injecting the entire volume of molten polymeric material into the mold in a couple of seconds, producing a higher rate of shear than DDM and typically yielding a smoother surface finish- afforded by the low surface roughness of the mold tool itself (Fig. 6).

\subsection{Bulk density calculations}

289 IM samples for each formulation had a bulk and true density of $0.94 \mathrm{~g} / \mathrm{cm}^{3}$ and zero porosity. Bulk density and porosity of VRs manufactured by DDM with an infill density of 10,50 or $100 \%$ were calculated for the infilled portions of the ring device. The outer walls of the DDM VRs were all printed at maximum density regardless of the infill density and this was accounted for in the porosity calculations. Linear regression analysis confirmed a correlation between decreasing ring infill density (\%) and increasing porosity for DDM printed rings manufactured using T87/DPV and T60/DPV $\left(r^{2}=0.99\right.$ for both) (Fig. 7).

\subsection{Drug Content}

298 Drug content assays indicated no significant change to DPV loading $(\% \mathrm{w} / \mathrm{w})$, following repeated thermal cycles during processing irrespective of formulation or manufacturing process. DPV content in T87 extrudate and VRs (DDM and IM) was 10.0 $\pm 0.02,10.0 \pm 0.1$ and $9.6 \pm 01 \%$ respectively. whilst for T60, content was $10.5 \pm 0.1,10.2 \pm 0.2$ and $9.8 \pm 0.1 \%$ respectively. 


\subsection{In vitro release}

305 Daily DPV release from TPU/DPV rings ranged between 333-8666 $\mu \mathrm{g}$ on day 1 and 193$992 \mu \mathrm{g}$ on day 29, with T60/DPV formulations showing a reduced maximum DPV release at most timepoints compared to T87 (Fig. 8). T87 and T60 DDM printed VRs with 10\% infill density (62 or $57 \mathrm{mg}$ DPV load) exhibited either a seven or four-fold increase in DPV release rate respectively compared to injection molded rings containing 190-194 mg DPV. For DDM printed rings, there was very significant correlation between decreasing ring density and increasing DPV release rate as a percentage of total drug loading. On day 1, there was no statistically significant difference $(\mathrm{P}>0.05)$ in DPV release from VRs with a $10 \%$ and $50 \%$ infill density or between VRs with a 100\% infill density manufactured by DDM and IM. By day 15 , the only groups which exhibited no statistically significant difference $(P>0.05)$ in terms of DPV release were VRs manufactured by DDM at $100 \%$ infill density and IM. This result indicates that VRs manufactured using the same formulation, but via IM or DDM at

317 full density, can produce similar daily release profiles for up to 29 days, and highlight the 318 potential for prototyping of drug delivery devices using the APF printing process. The total cumulative release across all rings with an infill density of $100 \%$ manufactured by IM or DDM was up to 4 or $10 \%$ of the total drug-loading respectively, while rings printed with an infill density of 50 or $10 \%$ (DDM) released up to 56 or $79 \%$ of the total DPV loading after 29 days. None of the VRs in the study experienced drug exhaustion, suggesting that DPV release could be extended beyond 29 days. For both TPU systems and all ring types, cumulative release $v s$. root time profiles were linear, with the T87/DPV system (Fig. 9) representative of the trend seen in the T60/DPV rings. Coefficient of variation $\left(\mathrm{R}^{2}\right)$ values were close to unity (0.97 to 0.99), indicating a permeation-controlled release mechanism for DPV from these rings. The diffusion-controlled nature of the dapivirine release and the fact that each device is 
manufactured using an identical formulation, suggests that the significant differences in release kinetics are most likely the result of the differences in surface area of the devices that are in contact with the in vitro release media. CAD modelling of the ring geometries (Fig. 10) indicates that IM rings have the lowest surface area, $1974 \mathrm{~mm}^{2}$, with DDM printed samples

332 having higher contact surface areas, with $100 \%, 10 \%$ and $50 \%$ densities correlating with areas of $2788,11,435$ and $19,152 \mathrm{~mm}^{2}$ respectively. These areas correlate with the increases in total cumulative masses of DPV released during the in-vitro studies (Fig. 8, B and E). Biofilms, including microbial aggregates and floccules that occur within implanted medical and drug delivery devices porous morphologies, have been well documented (Donlan and Costerton, 2002). Due to the porous morphologies of DDM VRs, important next steps will include assessment of the inherent nature of biofilm formation.

Daily DPV release from T87 VRs was up to 3-fold higher than from equivalent T60 VRs. Rings manufactured with the same infill density had similar calculated porosity and surface morphology, suggesting that differences in the daily release rate were inherent to the polymeric material used for drug encapsulation, specifically, differences in the polymers' chemical structures. T60 had a Shore durometer hardness of 60D and flexural modulus of higher proportion of hard segments than T87 and higher degree of crystallinity, potentially

347 explaining the differences observed in daily DPV release across formulations. It serves to 348 highlight the critical role of polymer selection drug delivery device design (Karavelidis et al., 349 2011; Shoaib et al., 2017).

\section{Conclusions}


352 For the first time, Arburg Plastic Freeforming has been used to create drug delivery devices 353 with a range of infill densities and correlating surface areas. The manufacturing time (up to $35417 \mathrm{~min}$ ) for DDM VRs (OD: $54.00 \mathrm{~mm}$, CSD: $4.00 \mathrm{~mm}$ ), could be reduced through 355 optimisation but the method presents additional challenges for large production scale batches 356 compared to conventional injection molding or hot melt extrusion. In order to be feasible for 357 additive manufacture, drug delivery devices would have to provide superior therapeutic 358 effects than those produced using well established techniques. Arburg Plastic Freeforming 359 offers a new additive manufacturing technique to either tune the release rate from 360 thermoplastic based drug delivery devices or to reduce the drug loading required to maintain 361 a desired dosage level compared to conventional thermoplastic processing techniques. 362 Although the dosage form reported in this work is a vaginal ring manufactured from a 363 flexible polyurethane, the technique may be useful for manufacture of a variety of tailored 364 geometries using polymer materials commonly used for injection molding. 
365 Acknowledgements

366 N.W. was supported by a Department for Education and Learning studentship. Dapivirine 367 was supplied by the International Partnership for Microbicides (IPM), which receives 368 generous support from the Danish Ministry of Foreign Affairs, Flanders Department of 369 Foreign Affairs, Irish Aid, the German Federal Ministry of Education and Research (BMBF) 370 through the KfW Development Bank, the Ministry of Foreign Affairs of the Netherlands, UK 371 aid from the British people, the American people through the United States Agency for 372 International Development (USAID) in partnership with the US President's Emergency Plan 373 for AIDS Relief (PEPFAR), and the Bill \& Melinda Gates Foundation.

374

375 Conflict of interest

376 All authors declare no actual or potential conflicts of interest.

377

378 Author contribution to manuscript

379 P.B. was the principal investigator on the project. All authors contributed to the design of the 380 study and drafting of the manuscript for submission. N.W. and P.B. performed the 381 experimental work. The manuscript was drafted by P.B., N.W. and R.K.M. All authors 382 provided input and review which further developed the manuscript. All authors approved 383 submission of the manuscript. 
Abdool, K.Q., Frohlich, J.A., Grobler, A.C., Baxter, C., Mansoor, L.E., Kharsany, A.B.M., Sibeko, S., Mlisana, K.P., Omar, Z., Gengiah, T.N., Maarschalk, S., Arulappan, N., Mlotshwa, M., Morris, L., Taylor, D., Abdool Karim, Q., Abdool Karim, S.S., Frohlich, J.A., Grobler, A.C., Baxter, C., Mansoor, L.E., Kharsany, A.B.M., Sibeko, S., Mlisana, K.P., Omar, Z., Gengiah, T.N., Maarschalk, S., Arulappan, N., Mlotshwa, M., Morris, L., Taylor, D., 2010. Effectiveness and safety of tenofovir gel, an antiretroviral microbicide, for the prevention of HIV infection in women. Science (80-. ). 329, 11681174. https://doi.org/10.1126/science.1193748

Alexandre, K.B., Mufhandu, H.T., London, G.M., Chakauya, E., Khati, M., 2016. Progress and perspectives on HIV-1 microbicide development. Virology 497, 69-80. https://doi.org/10.1016/j.virol.2016.07.004

Baeten, J.M., Palanee-Phillips, T., Brown, E.R., Schwartz, K., Soto-Torres, L.E., Govender, V., Mgodi, N.M., Matovu Kiweewa, F., Nair, G., Mhlanga, F., Siva, S., Bekker, L.G.G., Jeenarain, N., Gaffoor, Z., Martinson, F., Makanani, B., Pather, A., Naidoo, L., Husnik, M., Richardson, B.A., Parikh, U.M., Mellors, J.W., Marzinke, M.A., Hendrix, C.W., van der Straten, A., Ramjee, G., Chirenje, Z.M., Nakabiito, C., Taha, T.E., Jones, J., Mayo, A., Scheckter, R., Berthiaume, J., Livant, E., Jacobson, C., Ndase, P., White, R., Patterson, K., Germuga, D., Galaska, B., Bunge, K., Singh, D., Szydlo, D.W., Montgomery, E.T., Mensch, B.S., Torjesen, K., Grossman, C.I., Chakhtoura, N., Nel, A., Rosenberg, Z., McGowan, I., Hillier, S., Nair, F., Mhlanga, F., Siva, S., Bekker, L.G.G., Jeenarain, N., Gaffoor, F., Martinson, F., Makanani, B., Pather, A., Naidoo, L., Husnik, M., Richardson, B.A., Parikh, U.M., Mellors, J.W., Marzinke, M.A., Hendriz, C., van der Straten, A., Ramjee, G., Chirenje, Z.M., Nakabiito, C., Taha, T.E., Jones, J., Mayo, A., Scheckter, R., Berthiaume, J., Livant, E., Jacobson, C., Ndase, P., White, R., Patterson, R., Germuga, D., Galaska, B., Bunge, K., Singh, D., Szydlo, D.W., Montgomery, E.T., Mensch, B.S., Torjesen, K., Grossman, C.I., Chakhtoura, N., Nel, A., Rosenburg, Z., McGowan, I., Hillier, S., 2016. Use of a vaginal ring containing dapivirine for HIV-1 prevention in women. N. Engl. J. Med. 375, 2121-2132. https://doi.org/10.1056/NEJMoa1506110

Boyd, P., Fetherston, S.M., McCoy, C.F., Major, I., Murphy, D.J., Kumar, S., Holt, J., Brimer, A., Blanda, W., Devlin, B., Malcolm, R.K., 2016. Matrix and reservoir-type multipurpose vaginal rings for controlled release of dapivirine and levonorgestrel. Int. J. Pharm. 511, 619-629. https://doi.org/10.1016/j.ijpharm.2016.07.051

Clark, J.T., Johnson, T.J., Clark, M.R., Nebeker, J.S., Fabian, J., Tuitupou, A.L., Ponnapalli, S., Smith, E.M., Friend, D.R., Kiser, P.F., 2012. Quantitative evaluation of a hydrophilic matrix intravaginal ring for the sustained delivery of tenofovir. J. Control. Release 163, 240-248. https://doi.org/10.1016/j.jconrel.2012.08.033

Donlan, R.M., Costerton, J.W., 2002. Biofilms: Survival mechanisms of clinically relevant microorganisms. Clin. Microbiol. Rev. 15, 167-193. https://doi.org/10.1128/CMR.15.2.167-193

Duncan, G.W., 1970. Medicated devices and methods. US3545439A.

Espalin, D., Arcaute, K., Rodriguez, D., Medina, F., Posner, M., Wicker, R., 2010. Fused deposition modeling of patient-specific polymethylmethacrylate implants. Rapid Prototyp. J. 16, 164-173. https://doi.org/10.1108/13552541011034825 
Faheem, A., McCoy, C., McBride, M., Malcolm, K., Woolfson, D., Sparks, M., 2009. Simultaneous sustained release of maraviroc and dapivirine from silicone elastomer vaginal rings. In: 16th CROI Conference, (abstract 1069).

Fetherston, S.M., Boyd, P., McCoy, C.F., McBride, M.C., Edwards, K.-L.L., Ampofo, S., Malcolm, R.K., 2013. A silicone elastomer vaginal ring for HIV prevention containing two microbicides with different mechanisms of action. Eur. J. Pharm. Sci. 48, 406-415. https://doi.org/10.1016/j.ejps.2012.12.002

$\mathrm{Fu}, \mathrm{J} ., \mathrm{Yu}, \mathrm{X}$., Jin, Y., 2018. 3D printing of vaginal rings with personalized shapes for controlled release of progesterone. Int. J. Pharm. 539, 75-82. https://doi.org/10.1016/j.ijpharm.2018.01.036

Genina, N., Holländer, J., Jukarainen, H., Mäkilä, E., Salonen, J., Sandler, N., 2016. Ethylene vinyl acetate (EVA) as a new drug carrier for 3D printed medical drug delivery devices. Eur. J. Pharm. Sci. 90, 53-63. https://doi.org/10.1016/j.ejps.2015.11.005

Goyanes, A., Buanz, A.B.M., Hatton, G.B., Gaisford, S., Basit, A.W., 2015. 3D printing of modified-release aminosalicylate (4-ASA and 5-ASA) tablets. Eur. J. Pharm. Biopharm. 89, 157-162. https://doi.org/10.1016/j.ejpb.2014.12.003

Goyanes, A., Buanz, A.B.M.M., Basit, A.W., Gaisford, S., 2014. Fused-filament 3D printing (3DP) for fabrication of tablets. Int. J. Pharm. 476, 88-92. https://doi.org/10.1016/j.ijpharm.2014.09.044

Gupta, K.M., Pearce, S.M., Poursaid, A.E., Aliyar, H.A., Tresco, P.A., Mitchnik, M.A., Kiser, P.F., 2008. Polyurethane intravaginal ring for controlled delivery of dapivirine, a nonnucleoside reverse transcriptase inhibitor of HIV-1. J. Pharm. Sci. 97, 4228-4239. https://doi.org/10.1002/jps.21331

Johnson, T.J., Gupta, K.M., Fabian, J., Albright, T.H., Kiser, P.F., 2010. Segmented polyurethane intravaginal rings for the sustained combined delivery of antiretroviral agents dapivirine and tenofovir. Eur. J. Pharm. Sci. 39, 203-12. https://doi.org/10.1016/j.ejps.2009.11.007

Jonathan, G., Karim, A., 2016. 3D printing in pharmaceutics: A new tool for designing customized drug delivery systems. Int. J. Pharm. 499, 376-394. https://doi.org/10.1016/j.ijpharm.2015.12.071

Karavelidis, V., Karavas, E., Giliopoulos, D., Papadimitriou, S., Bikiaris, D., 2011. Evaluating the effects of crystallinity in new biocompatible polyester nanocarriers on drug release behavior. Int. J. Nanomedicine 6, 3021-3032. https://doi.org/10.2147/IJN.S26016

Koutsamanis, I., Eder, S., Beretta, M., Witschnigg, A., Paudel, A., Nickisch, K., Friedrich, M., Eggenreich, K., Roblegg, E., 2019. Formulation and processability screening for the rational design of ethylene-vinyl acetate based intra-vaginal rings. Int. J. Pharm. 564, 90-97. https://doi.org/10.1016/j.ijpharm.2019.04.041

Kraibuhler, H., Duffner, E., 2018. Device for the production of a three-dimensional object. 9889604.

Kraibuhler, H., Duffner, E., Kessling, O., 2018. Method for producing a three-dimensional object by means of generative construction. 10040249.

Kyobula, M., Adedeji, A., Alexander, M.R., Saleh, E., Wildman, R., Ashcroft, I., Gellert, P.R., Roberts, C.J., 2017. 3D inkjet printing of tablets exploiting bespoke complex geometries for controlled and tuneable drug release. J. Control. Release 261, 207-215. 
Landers, R., Mülhaupt, R., 2000. Desktop manufacturing of complex objects, prototypes and biomedical scaffolds by means of computer-assisted design combined with computerguided 3D plotting of polymers and reactive oligomers. Macromol. Mater. Eng. 282, 17-21. https://doi.org/10.1002/1439-2054(20001001)282:1<17::AIDMAME17>3.0.CO;2-8

480

481

482

483

484

485

486

487

488

489

490

491

492

493

494

495

496

497

498

499

500

501

502

503

504

505

506

507

508

509

510

511

512

513

514

515

516

517

518

519

Malcolm, R.K., Boyd, P.J., McCoy, C.F., Murphy, D.J., 2015. Microbicide vaginal rings: Technological challenges and clinical development. Adv. Drug Deliv. Rev. 103, 33-56. https://doi.org/10.1016/j.addr.2016.01.015

Maroni, A., Melocchi, A., Parietti, F., Foppoli, A., Zema, L., Gazzaniga, A., 2017. 3D printed multi-compartment capsular devices for two-pulse oral drug delivery. J. Control. Release 268, 10-18. https://doi.org/10.1016/j.jconrel.2017.10.008

McCoy, C.F., Murphy, D.J., Boyd, P., Derrick, T., Spence, P., Devlin, B., Malcolm, R.K., 2017. Packing Polymorphism of Dapivirine and Its Impact on the Performance of a Dapivirine-Releasing Silicone Elastomer Vaginal Ring. J. Pharm. Sci. 106, 2015-2025. https://doi.org/10.1016/j.xphs.2017.04.026

Mishell, D.R.J., Lumkin, M.E., 1970. Contraceptive effect of varying dosages of progestogen in silastic vaginal rings. Fertil. Steril. 21, 99-103.

Murphy, D.J., Desjardins, D., Dereuddre-Bosquet, N., Brochard, P., Perrot, L., Pruvost, A., Grand, R. Le, Lagatie, O., Vanhooren, L., Feyaerts, M., van Roey, J., Malcolm, R.K., 2014. Pre-clinical development of a combination microbicide vaginal ring containing dapivirine and darunavir. J. Antimicrob. Chemother. 69, 2477-2488. https://doi.org/10.1093/jac/dku160

Nel, A., Niekerk, N Van, Kapiga, S., Bekker, L.-G.G., Gamma, C., Gill, K., Kamali, A., Kotze, P., Louw, C., Mabude, Z., Miti, N., Kusemererwa, S., Tempelman, H., Carstens, H., Devlin, B., Isaacs, M., Malherbe, M., Mans, W., Nuttall, J., Russell, M., Ntshele, S., Smit, M., Solai, L., Spence, P., Steytler, J., Windle, K., Borremans, M., Resseler, S., Roey, J Van, Parys, W., Vangeneugden, T., Baelen, B Van, Rosenberg, Z., van Niekerk, Neliëtte, Kapiga, S., Bekker, L.-G.G., Gama, C., Gill, K., Kamali, A., Kotze, P., Louw, C., Mabude, Z., Miti, N., Kusemererwa, S., Tempelman, H., Carstens, H., Devlin, B., Isaacs, M., Malherbe, M., Mans, W., Nuttall, J., Russell, M., Ntshele, S., Smit, M., Solai, L., Spence, P., Steytler, J., Windle, K., Borremans, M., Resseler, S., Van Roey, Jens, Parys, W., Vangeneugden, T., Van Baelen, Ben, Rosenberg, Z., 2016. Safety and efficacy of a dapivirine vaginal ring for HIV prevention in women. N. Engl. J. Med. 375, 2133-2143. https://doi.org/10.1056/NEJMoa1602046

Okwuosa, T.C., Soares, C., Gollwitzer, V., Habashy, R., Timmins, P., Alhnan, M.A., 2018. On demand manufacturing of patient-specific liquid capsules via co-ordinated 3D printing and liquid dispensing. Eur. J. Pharm. Sci. 118, 134-143. https://doi.org/10.1016/j.ejps.2018.03.010

Promadej-Lanier, N., Smith, J.M., Srinivasan, P., McCoy, C.F., Butera, S., Woolfson, A.D., Malcolm, R.K., Otten, R.A., 2009. Development and evaluation of a vaginal ring device for sustained delivery of HIV microbicides to non-human primates. J. Med. Primatol. 38, 263-271. https://doi.org/10.1111/j.1600-0684.2009.00354.x

Rai, B., Teoh, S.H., Hutmacher, D.W., Cao, T., Ho, K.H., 2005. Novel PCL-based honeycomb scaffolds as drug delivery systems for rhBMP-2. Biomaterials 26, 37393748. https://doi.org/10.1016/j.biomaterials.2004.09.052 
Sánchez-Adsuar, M.., 2000. Influence of the composition on the crystallinity and adhesion properties of thermoplastic polyurethane elastomers. Int. J. Adhes. Adhes. 20, 291-298. https://doi.org/10.1016/S0143-7496(99)00059-7

Scoutaris, N., Alexander, M.R., Gellert, P.R., Roberts, C.J., 2011. Inkjet printing as a novel medicine formulation technique. J. Control. Release 156, 179-185. https://doi.org/http://dx.doi.org/10.1016/j.jconrel.2011.07.033

Shoaib, M., Bahadur, A., Iqbal, S., Rahman, M.S.U., Ahmed, S., Shabir, G., Javaid, M.A., 2017. Relationship of hard segment concentration in polyurethane-urea elastomers with mechanical, thermal and drug release properties. J. Drug Deliv. Sci. Technol. 37, 88-96. https://doi.org/10.1016/j.jddst.2016.12.003

UNAIDS, 2017. Fact Sheet - World AIDS Day 2017.

Van Damme, L., Profy, A., Laga, M., Kitchen, V., Wright, A., Depraetere, K., Rosenstein, I., Vandersmissen, V., Poulter, L., McKinlay, M., Van Dyck, E., Weber, J., 2000. A phase I study of a novel potential intravaginal microbicide, PRO 2000, in healthy sexually inactive women. Sex. Transm. Infect. 76, 126-130. https://doi.org/10.1136/sti.76.2.126

van Laarhoven, J.A.H., Kruft, M.A.B., Vromans, H., 2002. In vitro release properties of etonogestrel and ethinyl estradiol from a contraceptive vaginal ring. Int. J. Pharm. 232, 163-73.

Welsh, N., Mccoy, C.F., Murphy, D.J., Malcolm, R.K., Devlin, B., Boyd, P., 2018. Density Mediated Drug Release From Dapivirine Vaginal Rings Produced by Additive Manufacturing: Abstracts of the HIV Research for Prevention Meeting, HIVR4P, 21-25 October, 2018, Madrid. AIDS Res. Hum. Retroviruses 34, 1-407. https://doi.org/10.1089/aid.2018.5000.abstracts

Welsh, N., Wilson, M., Malcolm, R.K., Devlin, B., Boyd, P., 2016. 3D Printing of Microbicide Vaginal Rings: A Proof-of-Concept Study:Abstracts of the HIV Research for Prevention Meeting, HIVR4P, 17-20 October, 2016, Chicago, USA. AIDS Res. Hum. Retroviruses 32, 1-409. https://doi.org/10.1089/aid.2016.5000.abstracts 
Figure 1. Diagram of the Arburg Freeformer internal components.

Figure 2. TGA thermal trace for raw materials: T87 and T60 TPU polymers and powdered DPV drug ( $n=3$, representative data shown). Samples underwent a heating ramp from $25^{\circ} \mathrm{C}$ to $250^{\circ} \mathrm{C}$ at a rate of $20^{\circ} \mathrm{C} \mathrm{min}^{-1}$.

Figure 3. DSC thermal trace for model drug (DPV), T87/DPV and T60/DPV ( $n=3$, representative data shown). Drug-loaded samples were heated from either $-90^{\circ} \mathrm{C}(\mathrm{Q} 100)$, $50^{\circ} \mathrm{C}$ or $25^{\circ} \mathrm{C}(\mathrm{Q} 20)$ to $250^{\circ} \mathrm{C}$ at a rate of $20^{\circ} \mathrm{C} \mathrm{min}^{-1}$.

Figure 4. Mean max. force required to compress drug-loaded $(n=6)$ and commercial VRs $(\mathrm{n}=13)$ by a target distance of $5 \mathrm{~mm}$.

Figure 5. Digital microscopy images showing the base of T87/DPV VRs (outer diameter $54.00 \mathrm{~mm}$, cross-sectional diameter $4.00 \mathrm{~mm}$ ) with a (A) $10 \%$, (B) $50 \%$ and (C) $100 \%$ infill density fabricated by DDM

Figure 6. Digital microscopy images of (A) T87/DPV and (B) T60/DPV VRs (outer diameter $54.00 \mathrm{~mm}$, cross-sectional diameter $4.00 \mathrm{~mm}$ ) fabricated by IM.

Figure 7. Relationship between the \% infill densities of VRs manufactured by DDM and porosity

Figure 8. Daily release (mean $\pm S D, n=6$ ) of DPV from T87/DPV rings $(A)$ and T60/DPV rings (D), cumulative release ( $n=6$ ) of DPV from T87/DPV rings (B) and T60/DPV rings (E) and percentage cumulative release $(n=6)$ of DPV from T87/DPV (C) and T60/DPV rings (F), fabricated by IM or APF DDM using infill densities of 10 (R10), 50 (R50) or 100\% (R100) into $0.2 \%$ Tween solution.

Figure 9. Cumulative release (mean $\pm \mathrm{SD}, \mathrm{n}=6$ ) of $\mathrm{DPV}$ versus root time for T87/DPV rings fabricated by IM or APF DDM using infill densities of 10 (R10), 50 (R50) or 100\% (R100) into $0.2 \%$ Tween solution.

Figure 10. Vaginal ring segments modelled in CAD software with associated fluid accessible surface area values for the whole ring device. Digital microscopy $(\times 100)$ was taken of equivalent physical samples of T87/DPV rings fabricated by (A) IM, and DDM using print densities of (B) 100\%, (C) 50\% and (D) 10\%.

Table 1. Dimensional analysis of IM and DDM VRs ( $n=6)$ manufactured using T87/DPV or T60/DPV pellets. 


\section{Responses}

We thank the editor and reviewers for their supportive and constructive comments on our manuscript, which have been very helpful in directing us to further improve the quality of the manuscript.

Each of the reviewers' comments are specifically addressed below in blue text. All associated changes in the revised manuscript are defined by line number (Ln).

\section{Reviewer \#1}

\section{General Comments}

This $\mathrm{ms}$ is an interesting application of additive manufacturing to create vaginal rings with some useful properties. The MS is well written.

\section{Actionable comments}

1. In the introduction, the work by Fu et al, IJP 539 (2018) 75-82 should be referenced (3-D printed vaginal rings).

Response - We thank the reviewer for highlighting this missing and relevant reference. It has now been added. Ln49.

2. The full study (all ages) of the APSIRE and Ring Study should also be reported (not the ages wherein data were more favorable).

Response - We appreciate that there were age related differences in efficacy in the ASPIRE and Ring Study but did not feel that there was the appropriate scope within this manuscript to highlight them and provide a suitably detailed commentary on the many hypotheses for this outcome.

To make this statement more accurate and transparent, we have used the overall efficacy results for women across all ages in each of the trials which are much lower at 37 and $31 \%$ respectively. Ln75.

3. The last paragraph starts out mentioning demand for personalized medicine yet the balance of the paragraph is about the process for making rings. These two topics need to be tied together more clearly or the first sentence removed.

Response - This is a valid point and for this manuscript, the first sentence is less relevant and has been removed. Ln92

4. Results and Discussion. Please state the maximum processing temperature in the first sentence of 3.1.

Response - This has now been added. Ln228

5. In section 3.8, it appears that there is some inconsistency between porosity, which determines surface area, and release rates. In some cases the release rate is higher from a lower surface area ring (fig $8 \mathrm{~B}$ and $\mathrm{E})$. Is there an explanation for this finding?

Response - We have reviewed the data referred to in this comment but are not clear about what the issue is. In Fig 8B \& E, total cumulative release of DPV (in $\mathrm{mg}$ ) is plotted. The greatest release is observed in the vaginal rings printed with an in-fill density of $50 \%, 10 \%, 100 \%$ and then the injection molded samples respectively. These results correlate exactly with the surface areas calculated using the CAD modelling method, described in Fig 10. This correlation is described in the manuscript. Ln327-330. 


\section{Reviewer \#2}

\section{General Comments}

The article is well-written and clearly describes the first use of an additive manufacturing (AM) technique for the fabrication of DPV vaginal rings (VRs). A DPV VR is in the licensing phase for HIV prevention, providing important context to the study. The work is innovative and has two main strengths: (1) the Arburg Plastic Freeforming (APF) technique is compatible with traditional manufacturing methods (e.g., hot-melt extrusion and injection molding), such that the same thermoplastics can be used. This was done here as VRs were made from the same batch of DPV in PU pelletized granules using APF and injection molding (IM) in parallel. (2) the wide range of DPV release rates obtained with APF VR prototypes were all higher than the VR produced by IM, a stated goal. The manuscript convincingly describes the value of $\mathrm{AM}$ in the context of drug delivery biomedical device development. It is not yet another errand application of AM, of which there are many in the literature.

\section{Actionable comments}

1. The main concern lies with high porosity VR structures in the vaginal milieu. Porous morphologies have been shown to potentially provide ideal niches for microorganisms to colonize with associated safety concerns. This possibility needs to be discussed and addressed.

Response - We appreciate the referee's comments and agree this warrants investigating in the future. Text has been added to highlight this in the MS. Ln330-334.

2. It is also unclear what is the ultimate, long-term goal of the AM. The manuscript states that the results "highlight the potential for prototyping of drug devices using the APF printing process". If this means that there is no intention of manufacturing VRs using APF for larger studies due to scale limitations of the technique, then this needs to be discussed along with how the devices will be manufactured for scale-up. Otherwise, the study is academically interesting, but of little use to the field broadly.

Response - Additional detail has been added to MS to clarify the advantages of using Arburg Plastic Freeforming as an alternative to traditional manufacturing techniques.LN349-354.

3. Details on the APF system (make, model, etc.) need to be included in the methods section.

Response - We thank the referee for highlighting this omission. The detail has been added to Section 2.5. Ln150-151

\section{Reviewer \#3}

\section{General Comments}

The authors prepared dapivirine vaginal rings with the additive manufacturing or injection molding methods and the properties of them were explored. This study is interesting and sufficient scientific data are provided. The following comments are provided.

\section{Actionable comments}


1. The graphic abstract is too large and too many words exist. The right part is suggested to be reduced. The graph above the phrase "28 days dissolution testing" may be deleted. The size of Graphic Abstract is very limited.

Response - We have reviewed the graphical abstract and believe that it follows the author guidelines laid down by IJP. The images and text are to provide an immediate representation of the entire study for a reader to follow.

2. Now the term "3D printing" seems to be more used than the word "additative manufacturing". "3D printing" is also ususally used in the related articles pulished in Int J Pharm. So, "3D printing" is suggested to use in this article including the title and text.

Response - Additive manufacturing and 3d printing are synonyms for the same process. AM has been used preferentially within the MS as it was considered to be more relevant for pharmaceutical manufacturing.

3. Fu et al. has prepared progesterone vaginal rings using an FDM 3D printing technique and the rings have different shapes and show sustained release of drugs ( $\mathrm{Fu} \mathrm{J}$, et al. 3D printing of vaginal rings with personalized shapes for controlled release of progesterone. Int J Pharm. 2018, 539(1-2):7582). This literature should be cited.

Response - We thank the reviewer for highlighting this missing and relevant reference. It has now been added. Ln49.

4. The References [12] and [13] are the publications of the same authors of this article, which are meeting abstracts. They may not provide valuable information about 3D printed dapivirine vaginal rings. Their citations are suggested to be deleted.

Response - These references are publically available meeting abstracts that describe preliminary work on the additive manufacture of vaginal rings and are entirely relevant to the MS.

5. Fig. 2 and 3 may be combined. And the same symbols should be usded for the same samples.

Response - Fig 2 is a TGA trace indicating mass loss of sample with increasing temperature. Fig 3 is a DSC trace showing the enthalpy of the samples with increasing temperature - the two data sets are completely unrelated and could not be plotted on the same graph?

6. Section 2.2 should follow Section 2.6. In this section, what's the "drug-loaded polymeric blends"?

Response - Thermal analysis of raw materials was performed prior to ring manufacture and therefore was reported in the first instance. We have indicated the rationale for the inclusion of the thermal characterisation in the response to your comment 7 below.

Drug-loaded polymeric blends was replaced by TPU/DPV polymeric blends in Section 2.2. Ln 119.

7. I don't know why Section 3.1. Thermal analysis is stated at the first in Results and discussion. Thermal analysis is generally done after preparation of formulations. In this section, the title and content are unclear. What do the authors want to show? Effect of high temperature on the preparation process? The authors must indicate the aim and conclusion in the section title and content. Moreover, the same samples are suggested in TGA and DSC. In Fig. 2, the reason for a small peak around 175 oC? In Fig. 3, the investigation in the range of the temperature under 0 oC seems no sense. The preparation of vaginal rings was done under $195 \mathrm{oC}$ that was lower than the melting point of dapivirine so that the crystallines of dapivirine may exist in the drug polymer blends if no drugs were dissolved in the melted TPU. It is necessary to identify the state of dapivirine in the rings. Scanning electron microscopy or other physicochemical methods are suggested to show the possibly present small crystalline of dapivirine in the ring. Moreover, SEM can be also used for the samples after dissolution to show the state of rings after a certain time.

Response - We appreciate the referee's comments and suggestions. TGA analysis was performed prior to thermal processing to determine whether DPV was thermally stable at the maximum 
processing temperature, and therefore was reported in this order in the manuscript as we done in a number of published, peer reviewed articles. This is why the DSC was also reported at this point for continuity and flow of the MS.

In Figure 2 the small dip is part of the overall degradation experienced by the DPV. Degradation of DPV up to $240^{\circ} \mathrm{C}$ has been reported previously by other authors, including in the McCoy 2014 reference included in the manuscript. Ln233.

The negative temperature at the start of the DSC experiment, Fig 3, was used to see if it was possible to identify the glass transition temperature of the TPU material and if the DPV had any effect on this.

We are not clear around your comments regarding the solubilisation of DPV - the DSC technique was used to attempt to identify if any crystalline DPV was present in the blends after HME. Ln234-238. SEM whilst a useful technique to identify the possible presence of crystallised drug on the surface of the device, is not a quantitative technique.

\section{The required reference format of Int J Pharm must be used.}

Response - We are grateful for highlighting this error. The manuscript was drafted using the wrong reference format within the reference management software. It has now been corrected to the appropriate format for IJP.

\section{Reviewer \#4}

\section{General Comments}

Welsh et al have reported a droplet deposition modelling manufacture process, commonly used in inkjet printing, that has the capacity to produce medical devices that demonstrate controlled drug release kinetics.

In this particular study they used an anti-HIV drug, the NNRTI dapivirine which was poorly soluble and was used in its crystalline form during the deposition process. The release of the drug from the device was assessed over time and the drug, which had undergone a high temperature and pressure molten jetting to form the vaginal ring was measured by HPLC.

The paper is well-written and the data clearly presented. This technique has the advantage over traditional techniques in that the nature of the device can be altered in terms of surface area and thus infill densities. The authors prepared dapivirine vaginal rings with the additive manufacturing or injection molding methods and the properties of them were explored. This study is interesting and sufficient scientific data are provided. The following comments are provided.

\section{Actionable comments}

1. My major concern relates to the activity of the drug after going through the DDM process. Does the dapivirine retain anti-HIV activity after the high-temperature and pressure step? Would this be a common issue for any drug delivered by this process. This should at least be discussed and addressed by the authors in the discussion.

Response - We thank the reviewer for this insightful comment. DPV is a small molecule antiretroviral drug, which when chemically intact with offer therapeutic activity against HIV. Our validated HPLC methods (related substances assay) shows that the drug released from the rings is chemically intact. Furthermore, we would point to the thermal stability of the DPV based on TGA data that shows negligible mass loss up to the processing temperatures used in this study. We have unpublished NMR data that also confirms that the DPV is released intact from thermoplastic rings. The clinical DPV ring used in the two recent clinical trials that demonstrated efficacy were manufactured at temperatures of $185^{\circ} \mathrm{C}$ for $60 \mathrm{~s}$. There is also a significant body of published evidence that DPV remains chemically intact and retains its antiviral activity after processing at temperatures and pressures in polymeric systems. ((Gupta et al., 2008; Kaur et al., 2011; Major et al., 2013) 



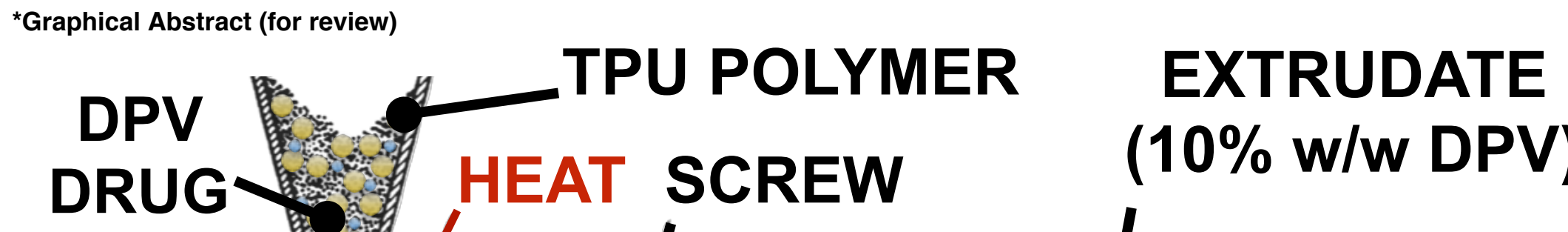

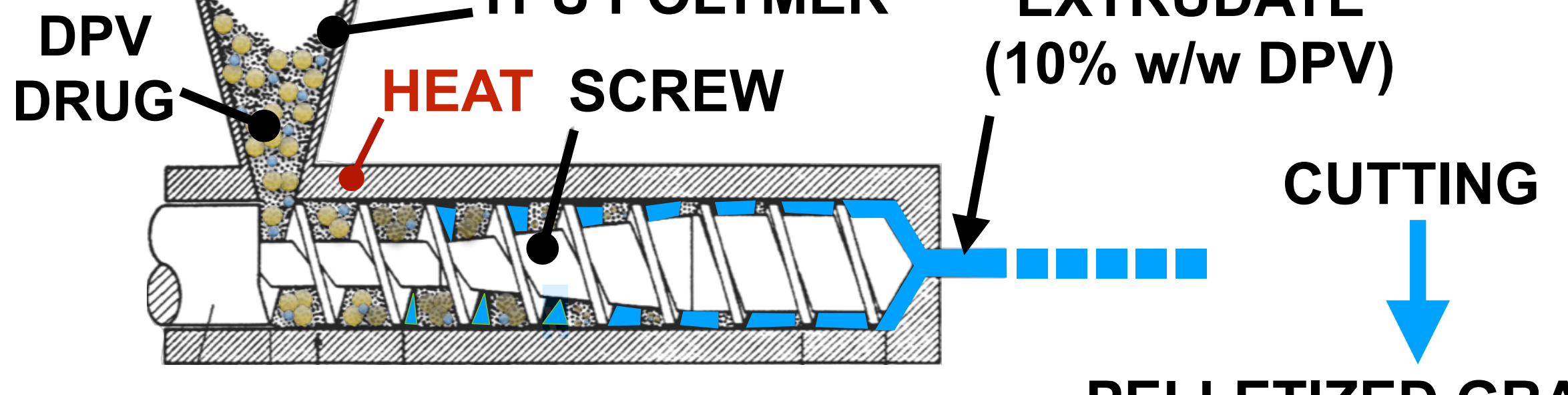

RING DENSITY (\%) AND MASS OF DPV IN

EACH RING TYPE

HOT MELT EXTRUSION

PELLETIZED GRANULES

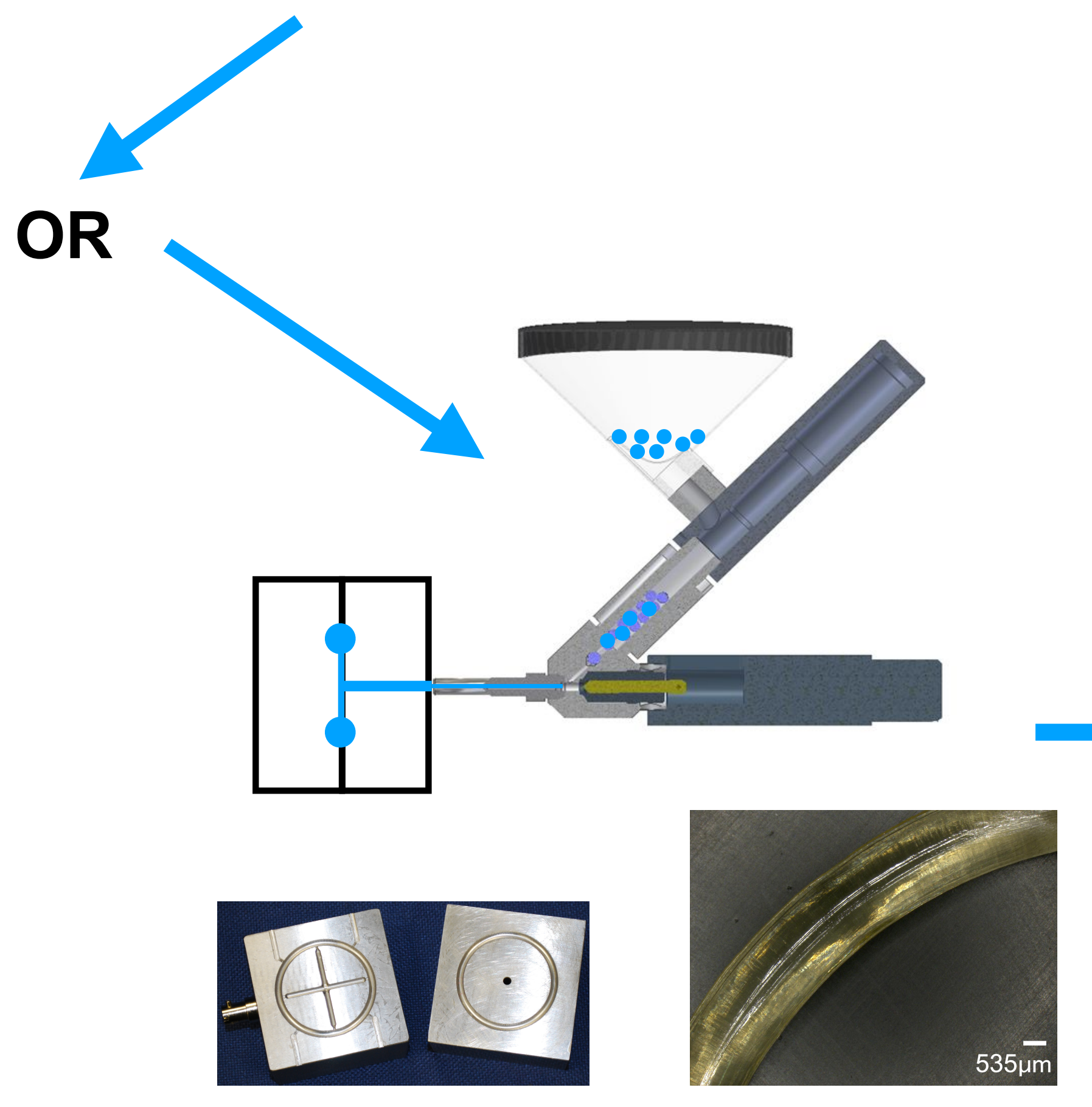

INJECTION MOLDING (IM)
28 DAY DISSOLUTION

TESTING

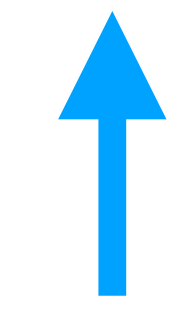

APF RINGS PRODUCED AT DIFFERENT CORE DENSITIES (10, 50 AND 100\%)

IM RINGS USED AS FULLY DENSE CONTROL SAMPLE

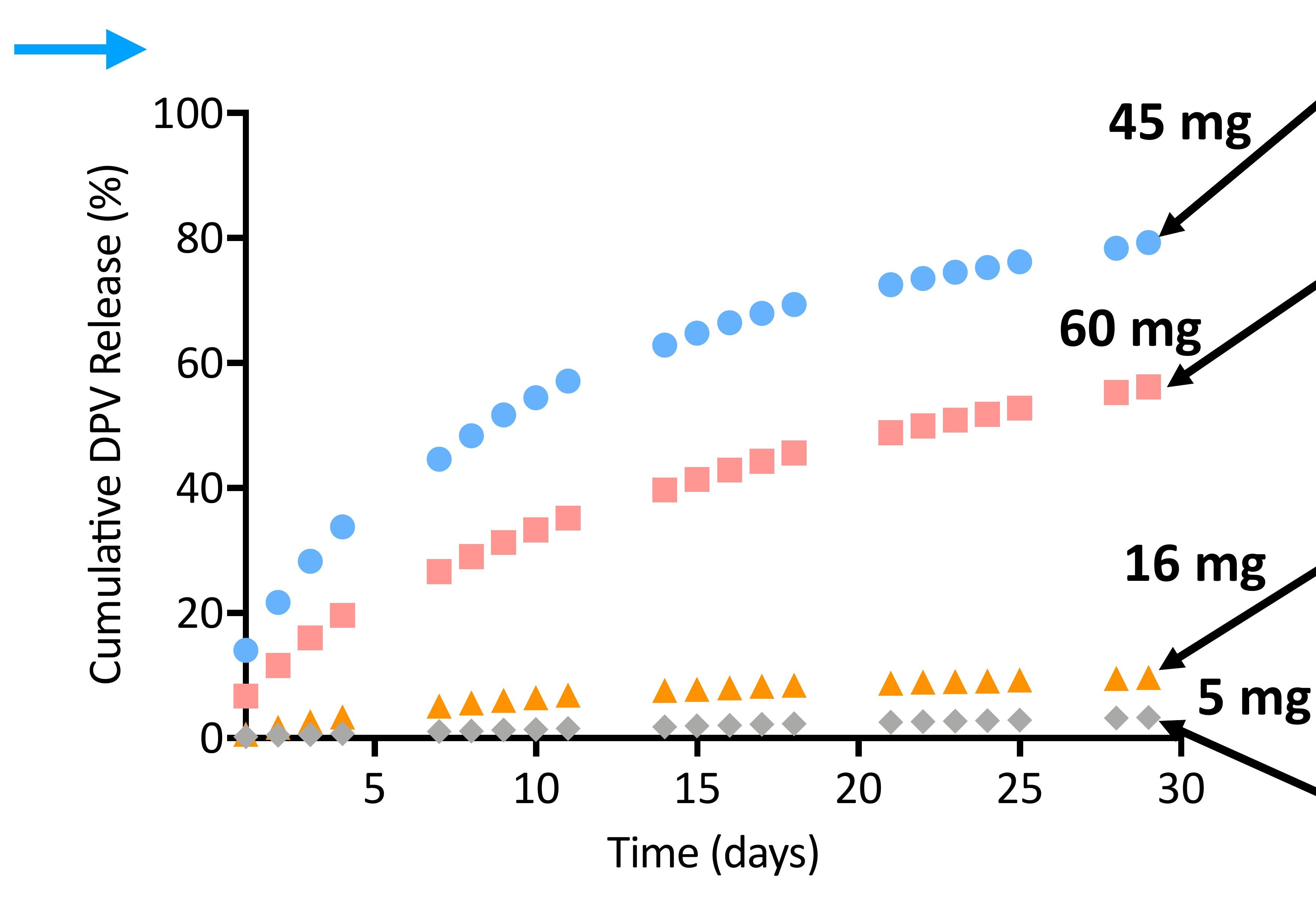

$62 \mathrm{mg}$

$50 \%$

$111 \mathrm{mg}$

$100 \%$

$181 \mathrm{mg}$

IM

$190 \mathrm{mg}$ 


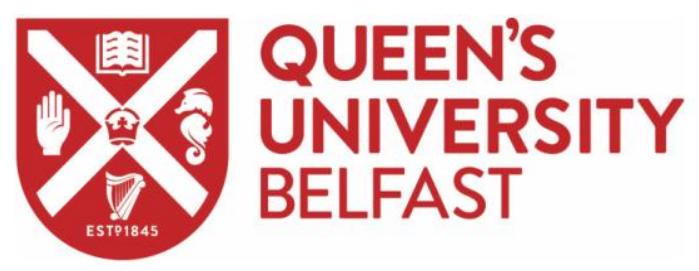

Monday 29 July 2019

\author{
Prof. Jürgen Siepmann \\ Editor-in-Chief \\ International Journal of Pharmaceutics
}

\title{
Dear Professor Siepmann,
}

Could you please consider our revised manuscript, entitled "Dapivirine-releasing vaginal rings produced by plastic freeforming additive manufacturing", for publication as an original research article in IJP, the International Journal of Pharmaceutics.

My name is Peter Boyd, Senior Lecturer in Pharmaceutical Engineering at the Queen's University Belfast. Research in my laboratories is focused on different aspects of controlled release drug delivery devices fabricated using polymeric excipients via injection molding and additive manufacturing and we work closely with Prof Karl Malcolm's group in the area of vaginal drug delivery.

We thank the reviewers for their helpful comments and have made a number of changes based on their suggestions.

In this manuscript, we describe for the first time, the use of an additive manufacturing (AM) technique based on high pressure material jetting of molten thermoplastic for the fabrication of dapivirine loaded vaginal rings. This research has the potential for significant impact in the field of pharmaceutical manufacturing and presents a new opportunity to produce drug delivery devices of varying geometries, densities and surface areas to give precise levels of control over the drug release kinetics using commonly available, injection molding grade thermoplastic materials. More specifically for HIV microbicides, it provides a new opportunity to increase the release of poorly water-soluble compounds in vaginal environments or to achieve desired dosing levels using lower drug loadings than those required using conventional thermoplastic processing techniques

We confirm that this manuscript has not been published elsewhere and is not under consideration by another journal. All authors have approved the manuscript for submission to IJP.

Sincerely,

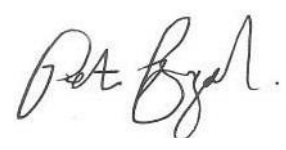

Peter Boyd

Senior Lecturer in Pharmaceutical Engineering

School of Pharmacy

Queen's University of Belfast

97 Lisburn Road

Belfast BT9 7BL

Northern Ireland, UK

T: +44 (0)28 90972623

E: p.boyd@qub.ac.uk 


\section{Declaration of Interest}

The authors declare no competing financial or personal interest. 
Table 1. Dimensional analysis of IM and DDM VRs ( $n=6)$ manufactured using T87/DPV or T60/DPV pellets.

\begin{tabular}{lllll}
\hline Sample (n=6) & $\begin{array}{l}\text { Manufacturing } \\
\text { technique }\end{array}$ & Mass $(\mathrm{g})$ & $\begin{array}{l}\text { Cross-sectional } \\
\text { diameter }(\mathrm{mm})\end{array}$ & $\begin{array}{l}\text { Outer diameter } \\
(\mathrm{mm})\end{array}$ \\
\hline T87/DPV & IM & $1.98 \pm 0.00$ & $3.97 \pm 0.09$ & $53.08 \pm 0.56$ \\
T60/DPV & IM & $1.98 \pm 0.02$ & $3.92 \pm 0.06$ & $53.30 \pm 0.33$ \\
T87/DPV R10 & DDM & $0.62 \pm 0.02$ & $4.12 \pm 0.25$ & $53.62 \pm 1.11$ \\
T87/DPV R50 & DDM & $1.11 \pm 0.03$ & $3.99 \pm 0.07$ & $53.70 \pm 0.49$ \\
T87/DPV R100 & DDM & $1.81 \pm 0.04$ & $4.00 \pm 0.06$ & $53.57 \pm 0.34$ \\
T60/DPV R10 & DDM & $0.56 \pm 0.03$ & $4.02 \pm 0.06$ & $53.40 \pm 0.21$ \\
T60/DPV R50 & DDM & $1.09 \pm 0.03$ & $4.00 \pm 0.05$ & $53.59 \pm 0.20$ \\
T60/DPV R100 & DDM & $2.03 \pm 0.03$ & $3.99 \pm 0.03$ & $53.57 \pm 0.19$ \\
\hline
\end{tabular}


Hopper holds pelletised material

Piezo actuator pulses nozzle closure mechanism

Discharge of individual droplets from the nozzle tip
Plasticising screw similar to injection molding produces material pressures up to 600 bar

\section{Part carrier platform moves in $X, Y$ and $Z$ planes}




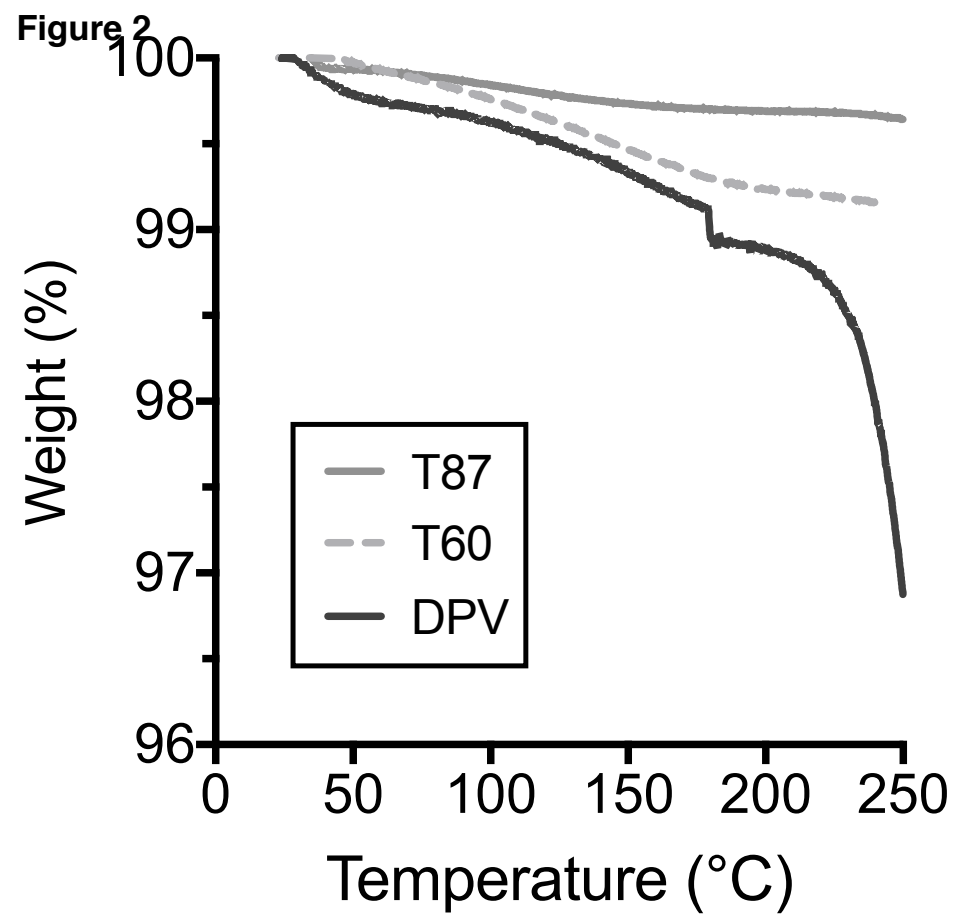




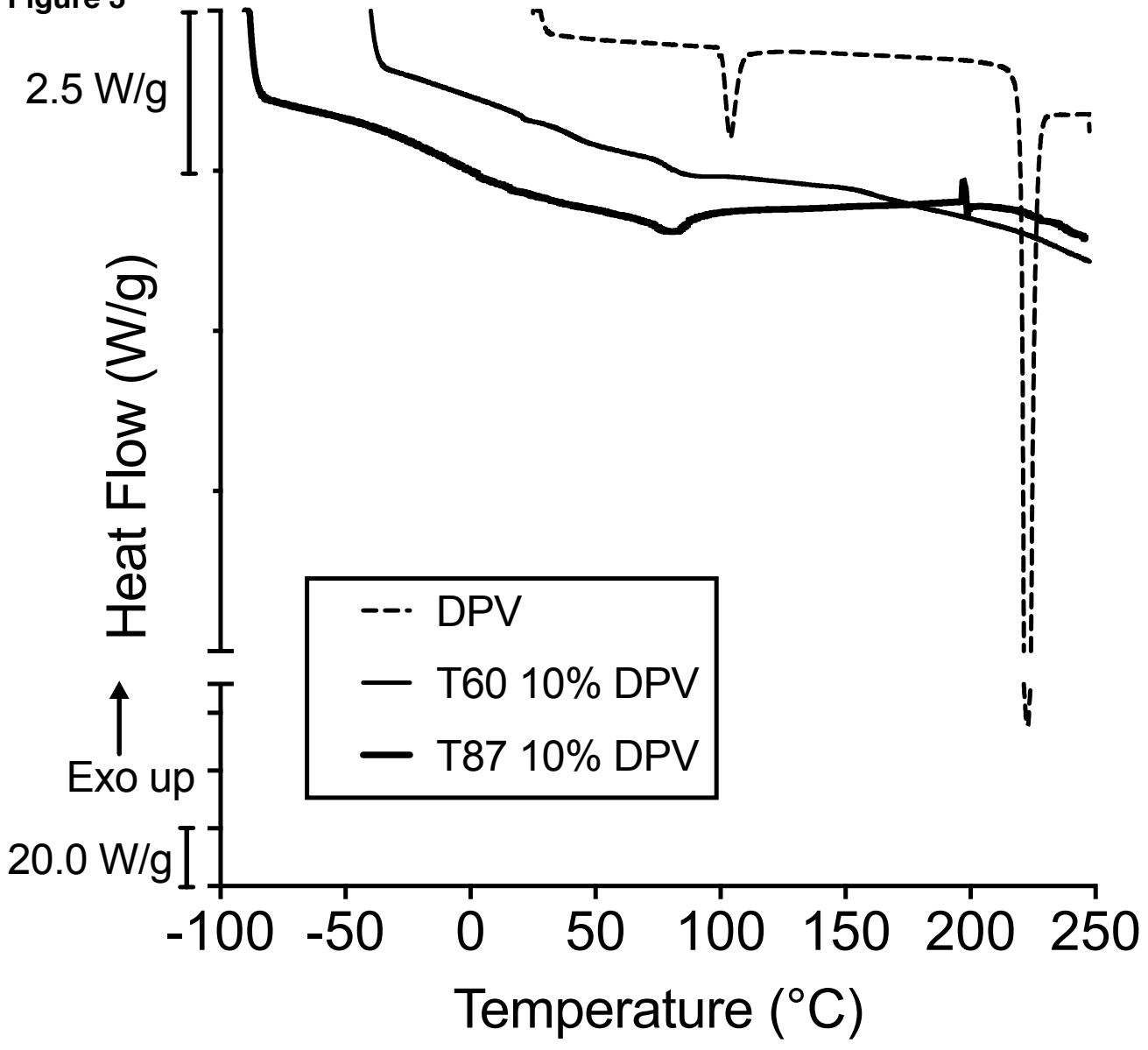


Figure 4

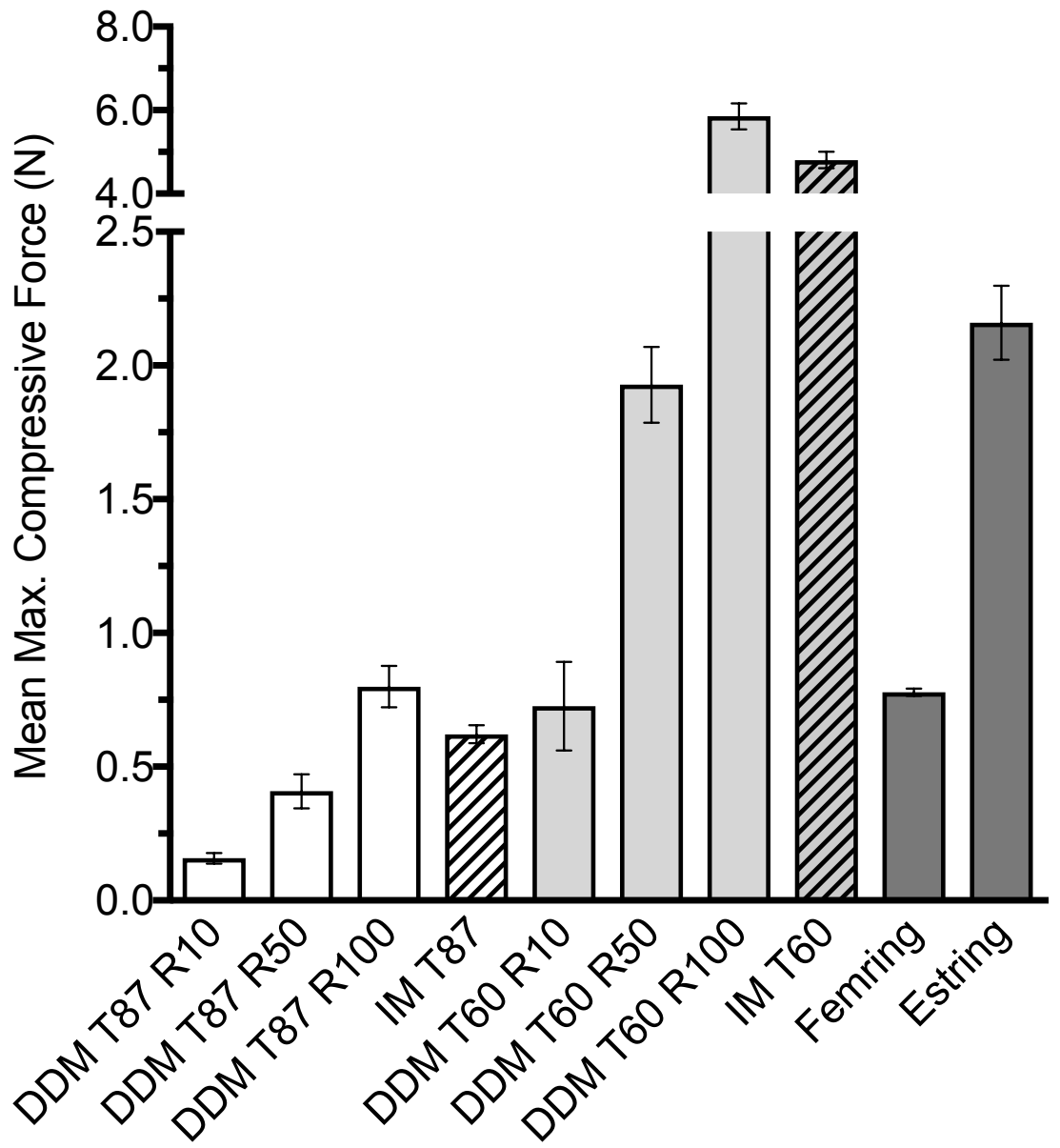


A

B

C 
A

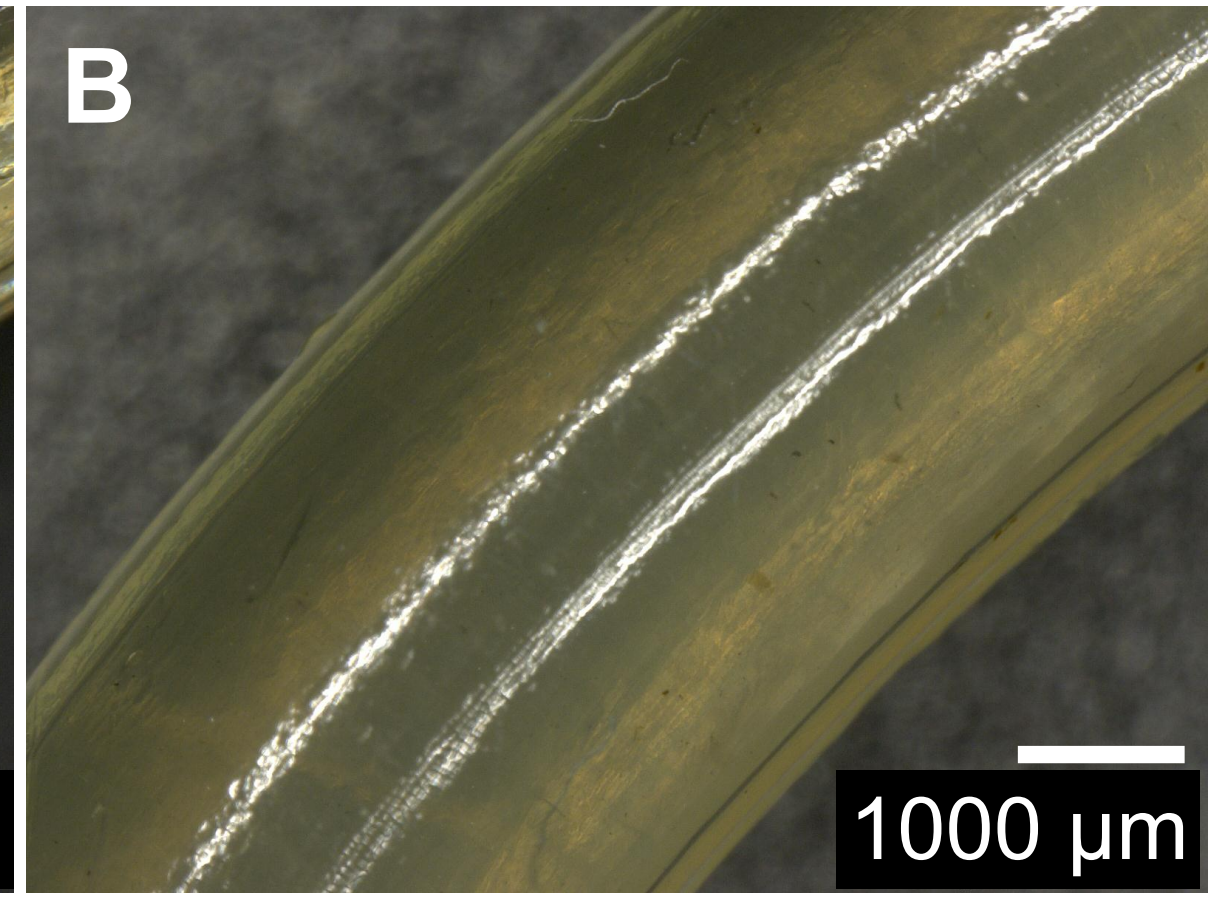


Figure 7

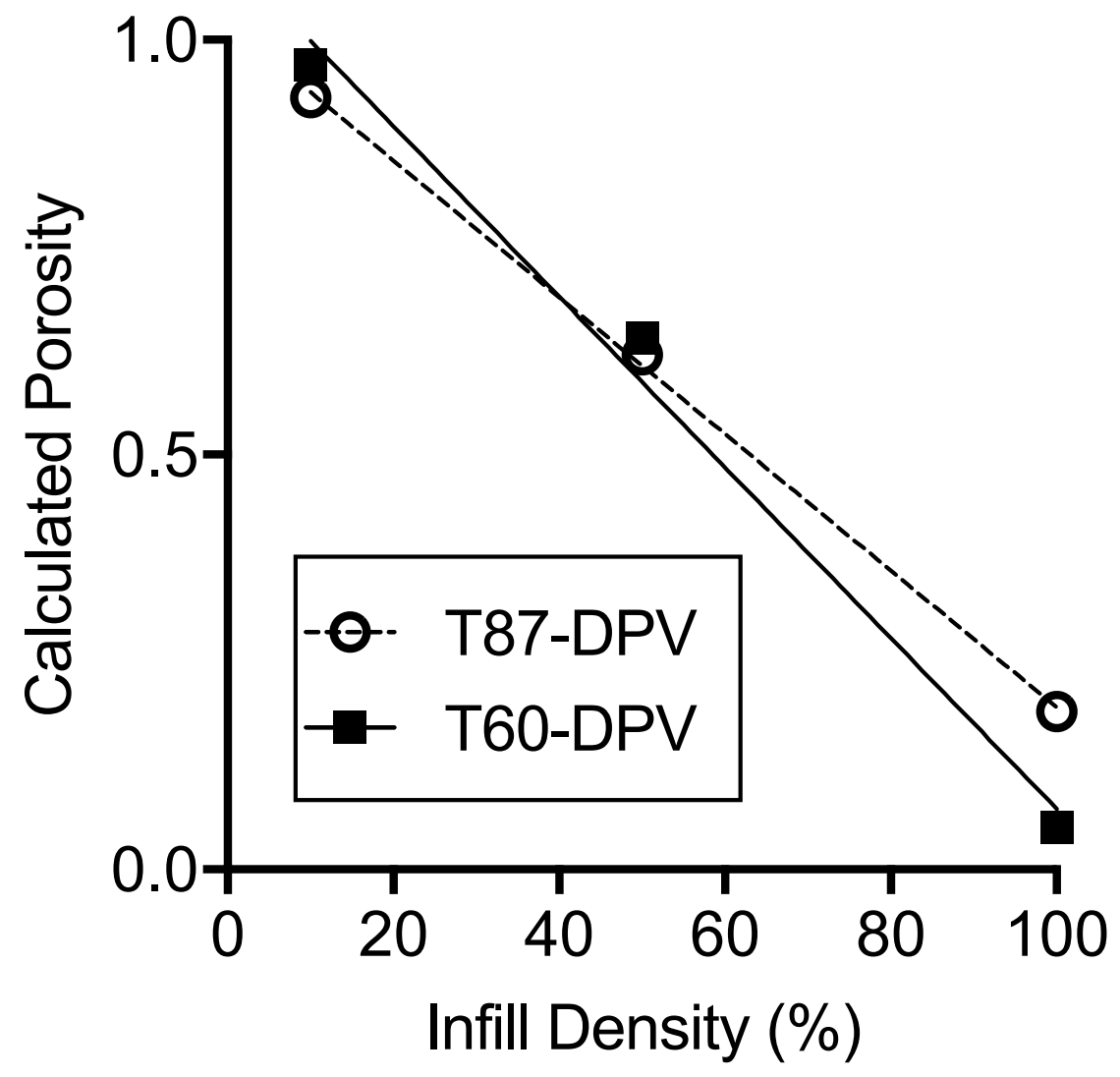


Figure 8
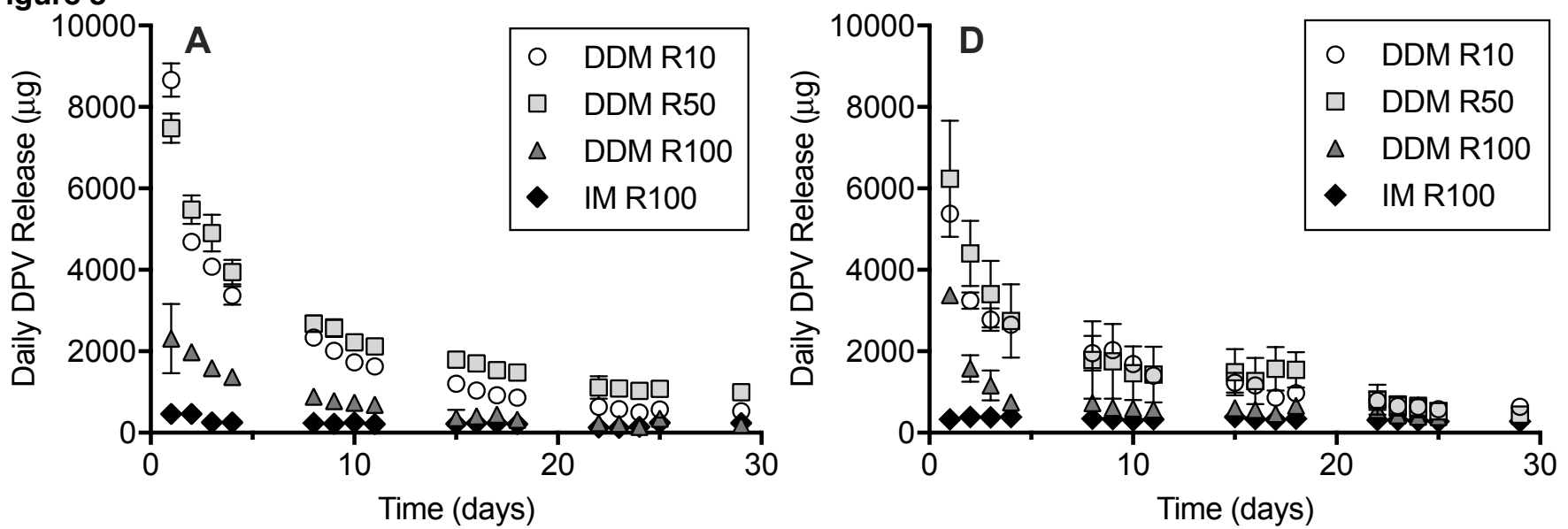

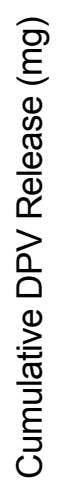
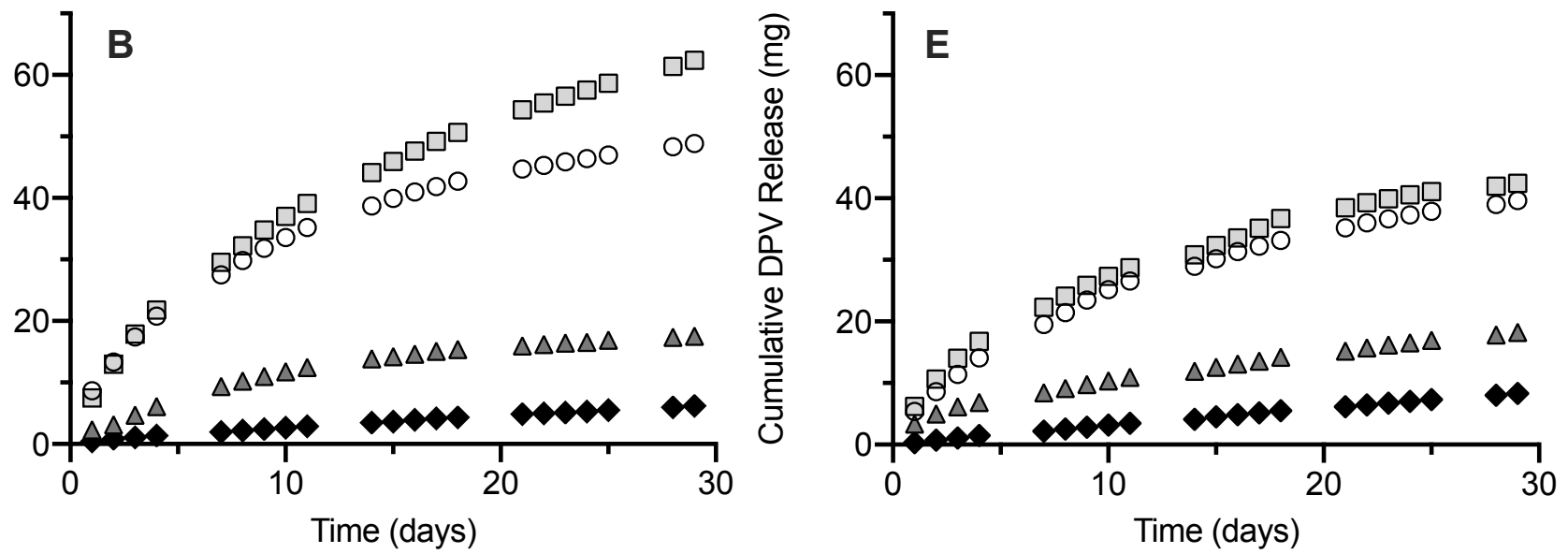

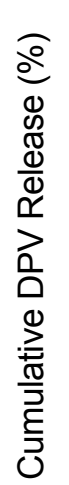
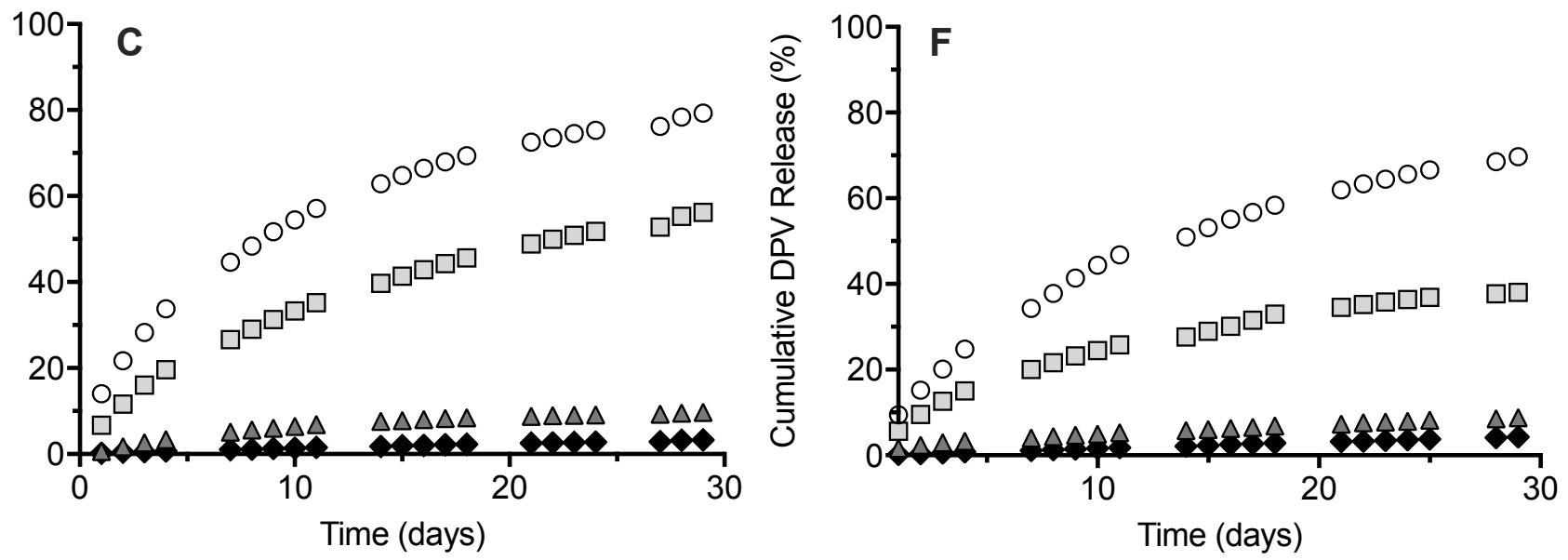
Figure 9

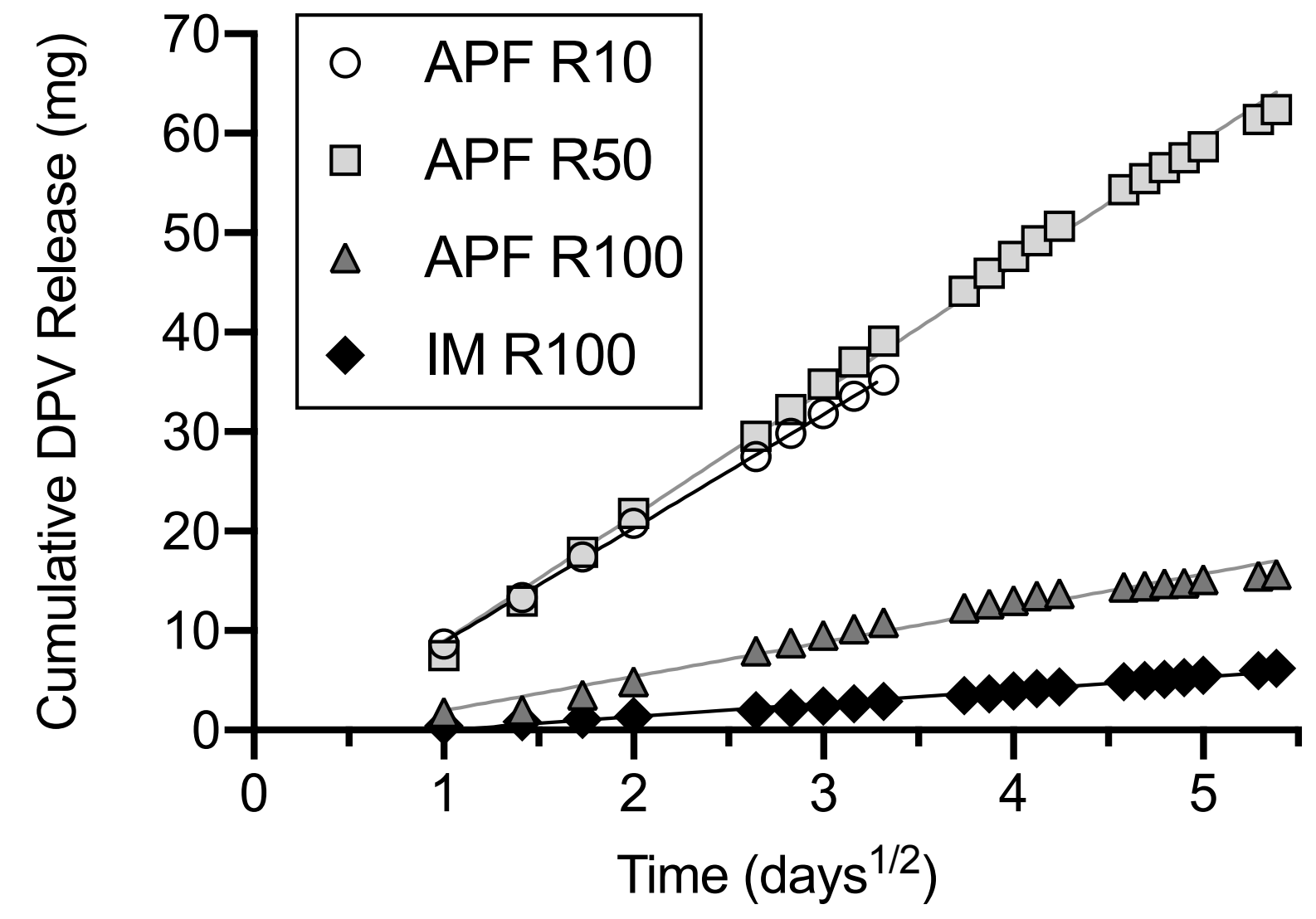


